University of Louisville

ThinkIR: The University of Louisville's Institutional Repository

Electronic Theses and Dissertations

$5-2012$

\title{
Specific $b$ alleles matter in phytopathogenic Ustilago maydis.
}

Kavita Burman Aulakh
University of Louisville

Follow this and additional works at: https://ir.library.louisville.edu/etd

\section{Recommended Citation}

Aulakh, Kavita Burman, "Specific b alleles matter in phytopathogenic Ustilago maydis." (2012). Electronic Theses and Dissertations. Paper 57.

https://doi.org/10.18297/etd/57

This Master's Thesis is brought to you for free and open access by ThinkIR: The University of Louisville's Institutional Repository. It has been accepted for inclusion in Electronic Theses and Dissertations by an authorized administrator of ThinkIR: The University of Louisville's Institutional Repository. This title appears here courtesy of the author, who has retained all other copyrights. For more information, please contact thinkir@louisville.edu. 


\title{
SPECIFIC $b$ ALLELES MATTER IN PHYTOPATHOGENIC USTILAGO MAYDIS
}

\author{
By
}

Kavita Burman Aulakh

B.Sc. (Hons.) Botany, University of Delhi, India, 2003

Thesis

Submitted to the Faculty of the

College of Arts and Sciences of the University of Louisville In Partial fulfillment of the Requirements for the Degree of

\author{
Master of Science
}

Department of Biology

Division of Molecular, Cellular and Developmental Biology

College of Arts and Sciences

University of Louisville

Louisville, Kentucky

May 2012 
Kavita Burman Aulakh

B.Sc. (Hons.) Botany, University of Delhi, India, 2003

A Thesis Approved on

April 25, 2012

By the following Thesis Committee:

Michael H. Perlin, Thesis Director

David Schultz

Jill Suttles 


\section{DEDICATION}

This thesis is dedicated to my dearest parents, in-laws

and

My loving husband 


\section{ACKNOWLEDGEMENTS}

By the grace of GOD I had good opportunities in my life to learn. I am grateful to my advisor Dr. Michael $\mathrm{H}$. Perlin for accepting me as his student. He supported and encouraged throughout my learning experiences. Also, I am thankful to Dr. David J. Schultz (committee member) for his valuable insights and directing my thought process in right direction. I am also thankful to Dr. Jill Suttles (committee member) for being supportive. I would also like to express my gratitude to Dr. Gary A. Cobbs (Professor) for helping me to understand experimental design and analyzing my research data. Without his expert guidance it would have been a challenge to analyze data.

I am glad to be a member of the Goat Lab. All my friends in the lab (Michael Cooper, Seth Adams, Janahvi Deshpande, Margaret Wallen and Susan Toh) were very supportive especially when I needed them the most. I would like to give a special thanks to Susan Toh for her help and I feel she is a friend indeed. I would also like to thank my ex goat lab friends, Dr. Charu Agarwal, Dr. Jinny A Paul and Dr. Charles Ben Lovely for playing a role in my learning and providing their help and support. Apart from Goat Lab my other friends Sanaya Bamji and Richa A. Singhal also helped and supported me during the time when I needed. 
I feel blessed to have a close-knit family who has supported me in all the aspects of my life especially my mother. She influences me a lot and always emphasizes - Simple Living, High Thinking and very importantly Self-Realization. Also, I am glad to have very supportive in-laws and husband. The warmth and care that I receive from them makes me feel lucky. 


\section{ABSTRACT \\ SPECIFIC $b$ ALLELES MATTER IN PHYTOPATHOGENIC USTILAGO MAYDIS}

Kavita Burman Aulakh

April 25, 2012

The smut fungus, Ustilago maydis is an obligate parasite on maize plants in order to complete its sexual life cycle. The haploid form is self-sterile but compatible mated cells undergo a dimorphic switch from yeast like to infectious dikaryotic filaments. Mating types are determined by two unlinked loci, the a locus and the $b$ locus. The a locus is involved in self and non-self cell recognition through production and sensing of pheromone. The $b$ locus of compatible mating types encodes a functional transcription factor that is involved in regulation of expression of genes responsible for filamentation, virulence and pathogenicity. Both loci co-ordinate through a conserved mitogen activated protein kinase (MAPK) signaling pathway for mating and the protein kinase $A(P K A)$ pathway in response to environmental conditions. If genes contributing to these signaling pathways are altered, some associated phenotypes appear to be either mating type or mating locus specific. Mating locus specific effects were evident in 
mutants of the p21-activated kinase (PAK), Smu1. Data from charcoal plate mating assays, plant infections and colony morphology in an ammonium deficient environment supports involvement of $b$ locus with function of smu1. Phenotypes associated with mutants of another PAK like kinase, Cla4 and over-expression of a vital small GTPase, Rho1, are dependent upon genetic background of the strain, but independent of the mating loci, as evident from charcoal plate mating assay. In addition, for cla4 mutants, cell morphology on rich media and colony morphology under low nitrogen condition were also studied and used to hypothesize that even in haploid cells, homeodomain proteins encoded by the $b$ locus may act as a functional transcription factor that interacts with certain components of signaling pathways so as to control various aspects of cell morphology and mating behavior. 


\section{TABLE OF CONTENTS}

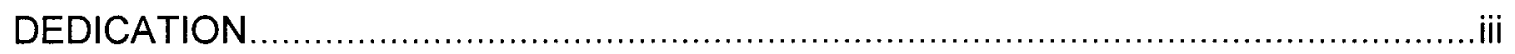

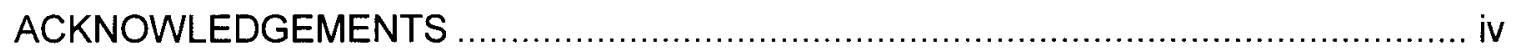

ABSTRACT

LIST OF TABLES

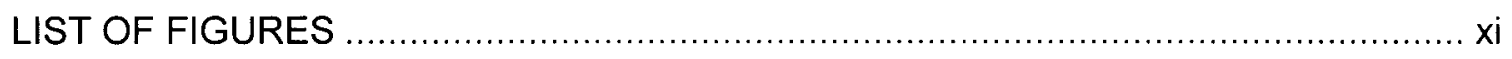

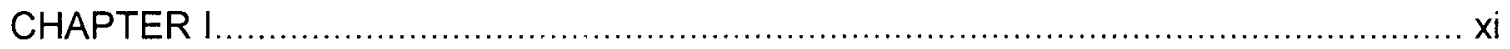

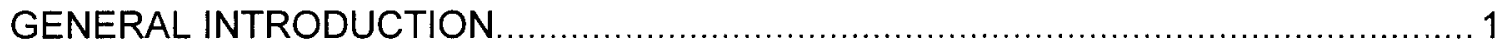

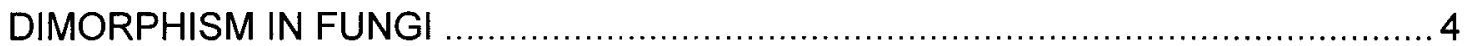

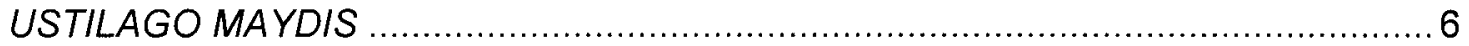

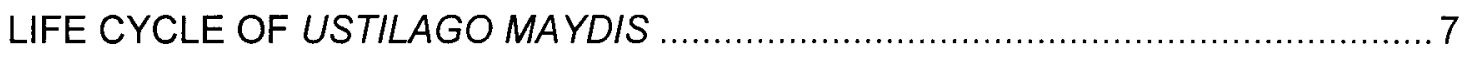

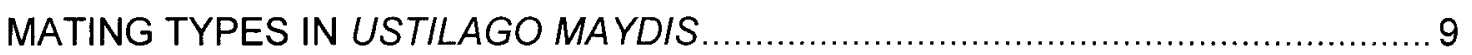

G-PROTEINS AND SMALL GTP-BINDING PROTEINS ….................................... 12

MITOGEN-ACTIVATED PROTEIN KINASE (MAPK) PATHWAY .......................... 14

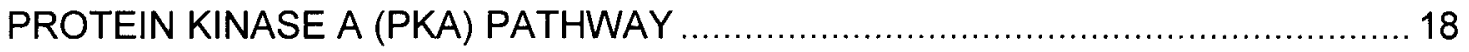

SMU1: STE20-LIKE PROTEIN KINASE WITH AN EFFECT ON USTILAGO MATING

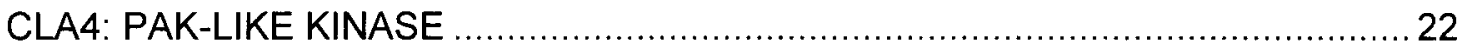

HSL7: A PUTATIVE ARGININE N-METHYLTRANSFERASE AND AN INTERACTOR

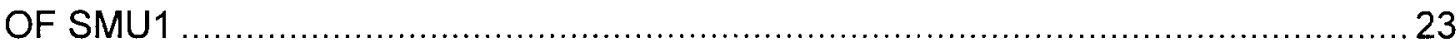

RHO1: A SMALL GTPASE AND AN INTERACTOR OF SMU1 …........................2 24

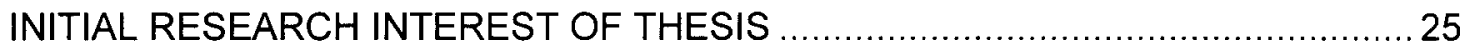

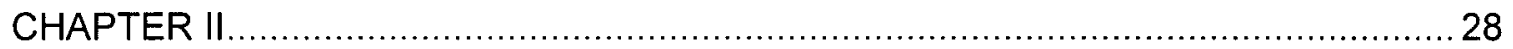

SPECIFIC $b$ ALLELES MATTER IN PHYTOPATHOGENIC USTILAGO MAYDIS .... 28

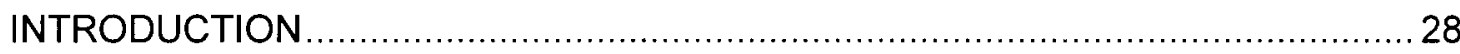

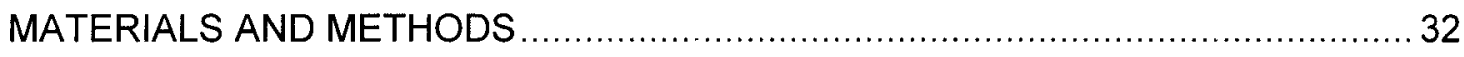

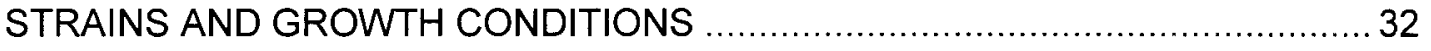

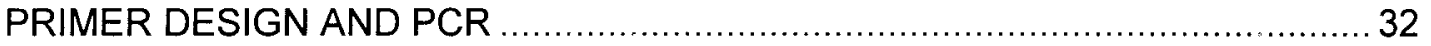

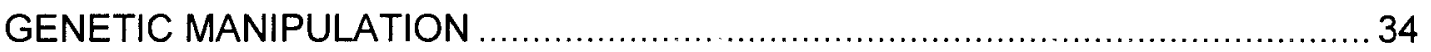


MATING ASSAY AND PLANT INFECTION ................................................. 35

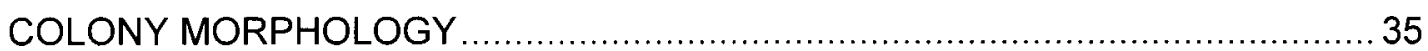

CELL MORPHOLOGY, STAINING AND MICROSCOPY ................................ 36

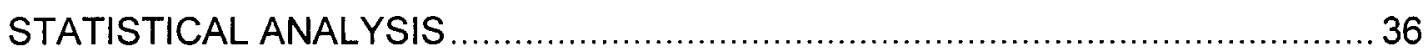

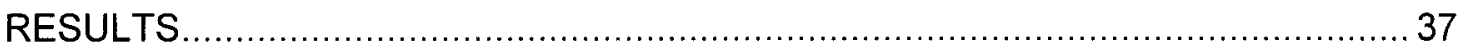

MATING EFFICIENCY AND PATHOGENICITY IN U. MAYDIS MUTANTS ........... 37

COLONY MORPHOLOGY IN U. MAYDIS MUTANTS …................................ 47

CELL MORPHOLOGY IN $\triangle$ CLA4 MUTANTS IN U. MAYDIS ............................50

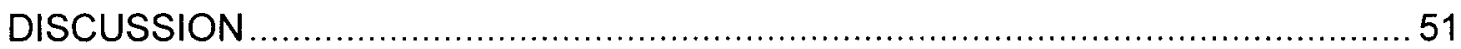

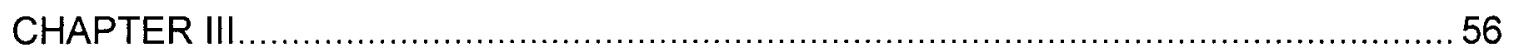

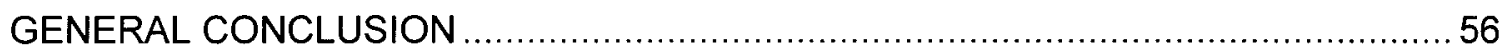

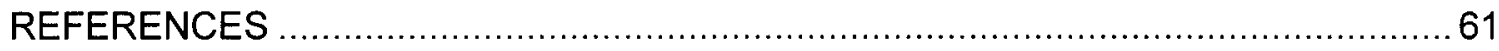

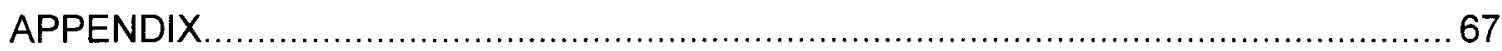

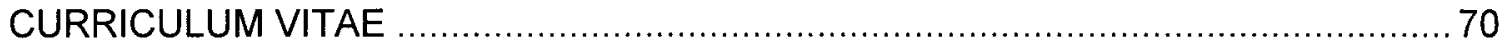




\section{LIST OF TABLES}

Table 1: Origin and genotypes of $U$. maydis strains .......................33

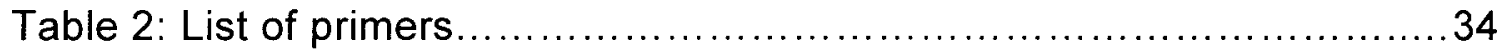

Table 3: Dunnett's $\mathrm{t}$ Test for Filamentation for smu1 mutants compared to

their respective parental WT as a control.................................49

Table 4: Dunnett's $\mathrm{t}$ Test for Filamentation for cla4 mutants compared to their respective parental WT as a control........................................49 


\section{LIST OF FIGURES}

Figure 1: Life cycle of corn smut, Ustilago maydis ........................... 8

Figure 2: Interactions between the two mating-type loci during development of $U$. maydis. 10

Figure 3: S. cerevisiae, three MAPK cascades and their shared components. 15

Figure 4: U. maydi,s, PKA pathway (Protein kinase A) on left and MAPK pathway (Mitogen activated pathway) on right. 17

Figure 5: S. cerevisiae. Signal transduction cascade: PKA (protein kinase A) pathway regulating pseudohyphal differentiation 19

Figure 6: Comparison of mating efficiency of $\Delta s m u 1$ mutants. 38

Figure 7: Statistical analysis of mating efficiency of $\Delta s m u 1$ mutants 38

Figure 8: Statistical analysis of disease indices for plant infection for $\Delta s m u 1$ mutants 39

Figure 9: Statistical analysis of mating efficiency of $\Delta s m u 1$ mutants across genetic background

Figure 10: Statistical analysis of disease indices for plant infection for $\Delta s m u 1$ mutants across genetic background.

Figure 11: Comparison of mating efficiency of smu1 over-expression mutants. 
Figure 12: Statistical analysis of mating efficiency of smu1 over-expression

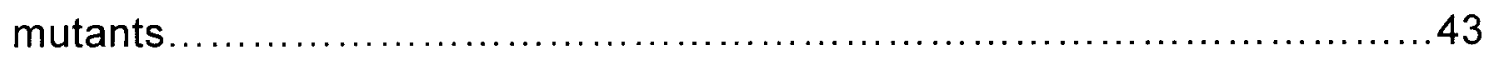

Figure 13: Comparison of mating efficiency of $\Delta c / a 4$ mutants...............45

Figure 14: Statistical analysis of mating efficiency of $\Delta c l a 4$ mutants .........45

Figure 15: Comparison of mating efficiency of rho1 over-expression

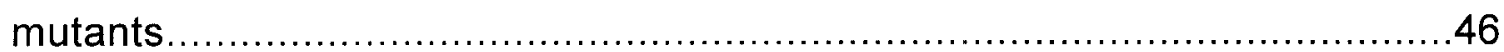

Figure 16: Statistical analysis of mating efficiency of rho1 over-expression

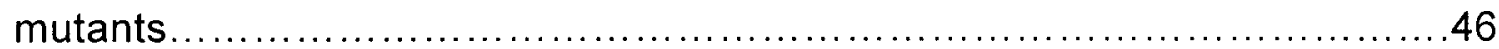

Figure 17: Colony morphology on SLAD medium ........................47

Figure 18: Cell morphology of $\Delta c / a 4$ mutants stained with calcoflour

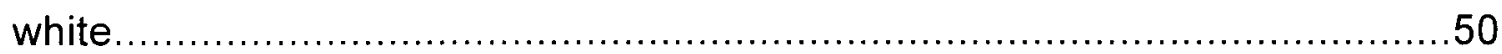

Figure 19: Comparison of mating efficiency of $\Delta s m u 1$ mutants..............53 


\section{CHAPTER I}

\section{GENERAL INTRODUCTION}

Fungi are classified as eukaryotes and they are found in their own kingdom within the classification of living organisms. Fungi possess some features of both plants and animals but are more closely related to animals than to plants (Lengeler et al., 2000). Fungal cells are surrounded by a cell wall like plant cells but fungal cell wall is composed of chitin whereas the cell wall of plants is made up of cellulose. Like animals, fungi are heterotrophic in terms of nutrition and mostly fungi store their sugars as glycogen. Fungal cells secrete enzymes on organic matter to digest it and to absorb nutrition. As for the cell structure, they can exist as unicellular forms, multicellular forms or fine microscopic filaments called hyphae. An intermingled network of hyphae is referred to as mycelium. Sometimes, they appear as mushroom-like fruiting bodies. Broadly, fungi are divided into two groups on the basis of identification of asexual and sexual stages in their life cycle. Fungi that reproduce asexually by mitosis only are referred to as 'Fungi Imperfectii' and fungi that can reproduce both by asexual (anamorphically) and sexual (teleomorphically) means are referred as 'Fungi Perfectii (Hoog, 2000). 
From the standpoint of humans, fungi have provided both benefits and detriments. For example, yeast (Saccharomyces cerevisiae) has for centuries been used for baking and in brewing alcoholic beverages. Fungi like Fusarium venenatum are eaten as a rich source of protein. Smutted corn which is a result of heavy fungal infection by Ustilago maydis is enjoyed as a delicacy in Mexico. In addition to nutritional or culinary value, many species of fungi have medicinal importance. Grifola frondosa (Maitake) has blood pressure lowering activity (Adachi et al., 1988). Low molecular weight compounds (like phenolic acids, flavonoids, tocopherols, carotenoids, sugars and fatty acids) present in wild mushrooms can reduce risk of breast cancer (Froufe et al., 2011). Many species possess antimicrobial activities (Benedict and Brady, 1972). As mentioned above, fungal cells cannot photosynthesize but some have the remarkable ability to radiosynthesize - melanized radiotrophic fungi like Cladosporium sphaerospermum can utilize ionizable gamma rays for their growth and development (as observed on the walls of melted nuclear reactor after the Chernobyl disaster in Ukraine) (Dadachova et al., 2007). Due to this ability radiosynthetic fungi can be put to work in space for capturing energy. Another significant role of fungi in human life is that they contribute in transforming barren land into fertile soil. Algal cells when present in association with fungal hyphae are called Lichens. Lichens have great ability to colonize barren land in a pollution free environment and help in imparting fertility to the soil (Gombert et al., 2005). A root symbiotic Arbuscular mycorrhizal fungus (AMF) Glomus irregulare significantly inhibits growth of the potato pathogen Fusarium 
sambucinum and reduces gene expression of the mycotoxin, trichothecenes. Mycotoxin trichothecenes if ingested by animals or humans can cause health problems (Ismail et al., 2011).

The other aspect of fungal interactions that affect humans is their potential negative impacts. Many fungal species can be thought of as "non-friendly" when they start feeding on our food or causes diseases. Colletotrichum falcatum destroys sugarcane stems by causing red rot. Erysiphe graminis infects barley and causes powdery mildew disease. Many of us may be familiar with the famine that inflicted such hardships on the Irish people during the 1800's. It was a fungus, Phytopthora infestans, which destroyed potatoes, their main food crop (Ristaino, 2002). It is also interesting to note that the genus Fusarium on one hand holds species which are a good source of protein, but on the other hand includes Fusarium graminearum which infects wheat (Boenisch and Schafer, 2011) and the Fusarium solani complex, that are animal pathogens. The mycotoxin zearalenone produced by many species of Fusarium induces cell death through p53 and the mitogen activated protein kinase (MAPK) signaling pathway (Yu et al., 2011). The mycotoxin citrinin is produced by Penicillium citrinum which inhibits tubulin polymerization and results in G2/M cell cycle arrest (Chang et al., 2011). Dermatophytes like Microsporum gypseum cause ringworm lesions on horses, camels and other animals, as a consequence of which there is loss of hair, and skin becomes patchy and flaky (Mahmoud, 1993). Also, there are opportunistic fungi like $C$. neoformans, which infects immune-compromised humans and sometimes leads to death. It exists in two forms smooth colony (SC) 
and mucoid colony $(\mathrm{MC})$. SC forms undergo switch to $\mathrm{MC}$ forms by changes in the capsular polysaccharide. MC form is virulent and escapes host immune response (Fries et al., 2001).

In addition to the above mentioned positive and negative aspects, among eukaryotes, single-celled fungi can be excellent organisms for experimental studies. The Ascomycete, S. cerevisiae is the best studied eukaryote to date, as it is easy to manipulate under laboratory settings. Another useful model organism for study of fungal pathogens is $U$. maydis, the basidiomycetous pathogen of maize. Finally, one positive thing about studying fungi is that we do not need special permission from institutional or governmental animal care units and work with these organisms does not prompt protests by animal rights groups. One critical feature of both $S$. cerevisiae and $U$. maydis that they share with a large number of other fungi is the characteristic known as dimorphism. This aspect of fungal development and differentiation (discussed in greater detail below) provides both interesting area for basic science investigation, as well as practical importance in our efforts to limit the abilities of some fungi to cause disease.

\section{DIMORPHISM IN FUNGI}

Fungi can exist as unicellular, multicellular or hyphal forms. Many fungi have evolved the ability to undergo a dimorphic switch, e.g., a single celled yeast-like fungus can become filamentous or vice versa. The conditions under which they switch from one form to another vary from species to species. $S$. cerevisiae exists as a unicellular, budding yeast form in a nutritionally rich 
environment, i.e., sufficient carbon and nitrogen. If there is limitation of nitrogen and abundant fermentable carbon (such as glucose) then cells divide but fail to separate leading to filamentous form (pseudohyphae), as if cells were in search of nitrogen (Nadal et al., 2008). The human and animal pathogen, Histoplasma capsulatum, exists in filamentous form at $25^{\circ} \mathrm{C}$ but when it comes in contact with blood serum at $37^{\circ} \mathrm{C}$ under moist conditions, it converts to an infectious yeast form (Conant, 1941). In contrast, Candida albicans becomes infectious under the same conditions as Histoplasma capsulatum but the pathogenic phase is filamentous rather than yeast-like budding (Nadal et al., 2008). C. albicans can also filament under nutrient limiting conditions and in response to basic $\mathrm{pH}$. The process of dimorphism is reversible in case of $C$. albicans. But in fungus like $U$. maydis, it is not a freely reversible process. U. maydis has both asexual and sexual phases in its life cycle. During asexual budding, cells are yeast-like and non-pathogenic. During the sexual phase, under optimal conditions, i.e., close proximity of opposite mating type partners and availability of host plant for subsequent cues, yeast-like cells undergo dimorphic switch and becomes filamentous. Once cells become filamentous they have to complete their sexual life cycle. This filamentous phase is pathogenic to corn (host) plant and produces galls on aerial parts (Nadal et al., 2008). In addition to mating pheromones and host cues, the haploid $U$. maydis cells can switch to filamentous form under nitrogen limiting, acidic pH conditions and exposure to lipids (Klose et al., 2004).

From a molecular level standpoint, it is important for a cell to reorganize its cytoskeleton and modify cell wall to exhibit polarized growth and undergo 
morphological changes like dimorphism. Various genes are involved that aid in such a transition, especially genes that encode small GTP-binding proteins and G-proteins. These genes are involved in conserved signaling pathways like Mitogen-Activated Protein Kinase (MAPK) and Protein Kinase A (PKA) (GarciaPedrajas et al., 2008). Fungal cell walls are mainly composed of $60 \%$ of $1,3-\beta-$ glucan, $40 \%$ of mannoproteins, and about $1 \%$ of chitin. Due to cross linking bonds among these three components the cell wall becomes rigid in nature. So, for a fungal cell to undergo a switch in its morphological state, it has to modify components of cell wall in a highly regulated manner, which is accomplished with the help of small GTPases (Smits et al., 2001).

\section{USTILAGO MAYDIS}

U. maydis is a member of group "Fungi Perfectii" as sexual reproduction is defined and hyphal forms are septate. In the kingdom Fungi, U. maydis belongs to subkingdom Dikarya and phylum Basidiomycota because in its sexual life cycle there is a stage when filaments possess two nuclei, one from each parental mating type; later, basidiospores are produced on a basal support called "Basidia". U. maydis tries to complete its sexual life cycle and becomes an obligate parasite on either maize (Zea mays) or teosinte (Euchlena mexicana).

As a result of infection, it penetrates aerial plant parts and produces galls. The infected corn referred as huitlacoche has been consumed as a delicacy in Mexico for centuries. It is used in soup preparations and as filling in quesadillas. It originated from ancient Aztec cuisine and is used as a cash crop in Mexico. Corn is a worldwide crop and is used as food, feedstock, and fiber. Corn is also 
important for biofuel and pharmaceutical industry. Due to galls produced, the corn crop is damaged which is a concern to corn producers and industries worldwide. In the US, $\$ 1$ billion ( $1 \%$ of total cost) is lost annually due to infection of corn plant which is caused by U. maydis (National Corn Growers Association). $U$. maydis is an excellent model organism for genetic studies as genes can be effectively disrupted by homologous recombination. Initial genetic observations like DNA recombination, repair, and mutation were studied in $U$. maydis (Holliday, 2004). A complete genome sequence of $U$. maydis, generated by the Broad Institute is available online and at the MIPS Ustilago maydis database (http://mips.helmholtz-muenchen.de/genre/proj/ustilago). All these features make U. maydis an excellent model for studying plant-pathogen interaction.

\section{LIFE CYCLE OF USTILAGO MAYDIS}

The life cycle of $U$. maydis (Figure 1) has both anamorphic and teleomorphic phases. In the anamorphic phase, cigar-shaped haploid basidiospores undergo mitotic division to multiply asexually. In the teleomorphic phase, sporidia with compatible mating types should be close to each other to sense pheromones secreted by opposite mating type sporidia. After this, conjugation tubes arising from each sporidia of opposite mating type fuse to form a dikaryotic filament. The dikaryotic filament in absence of host may undergo karyogamy and exist as diploid in nature. These diploid cells bud off to multiply.

But in the presence of host plant, dikaryotic hyphae become infectious. Infectious filaments produce appresoria from which invasive hypha emerges and find its way through natural openings like stoma or stigma to invade host plant (Ruiz- 
Herrera and Martinez-Espinoza, 1998). An appresorium is a head like structure formed at an apical region of the growing hypha due to compression of cytoplasmic content.

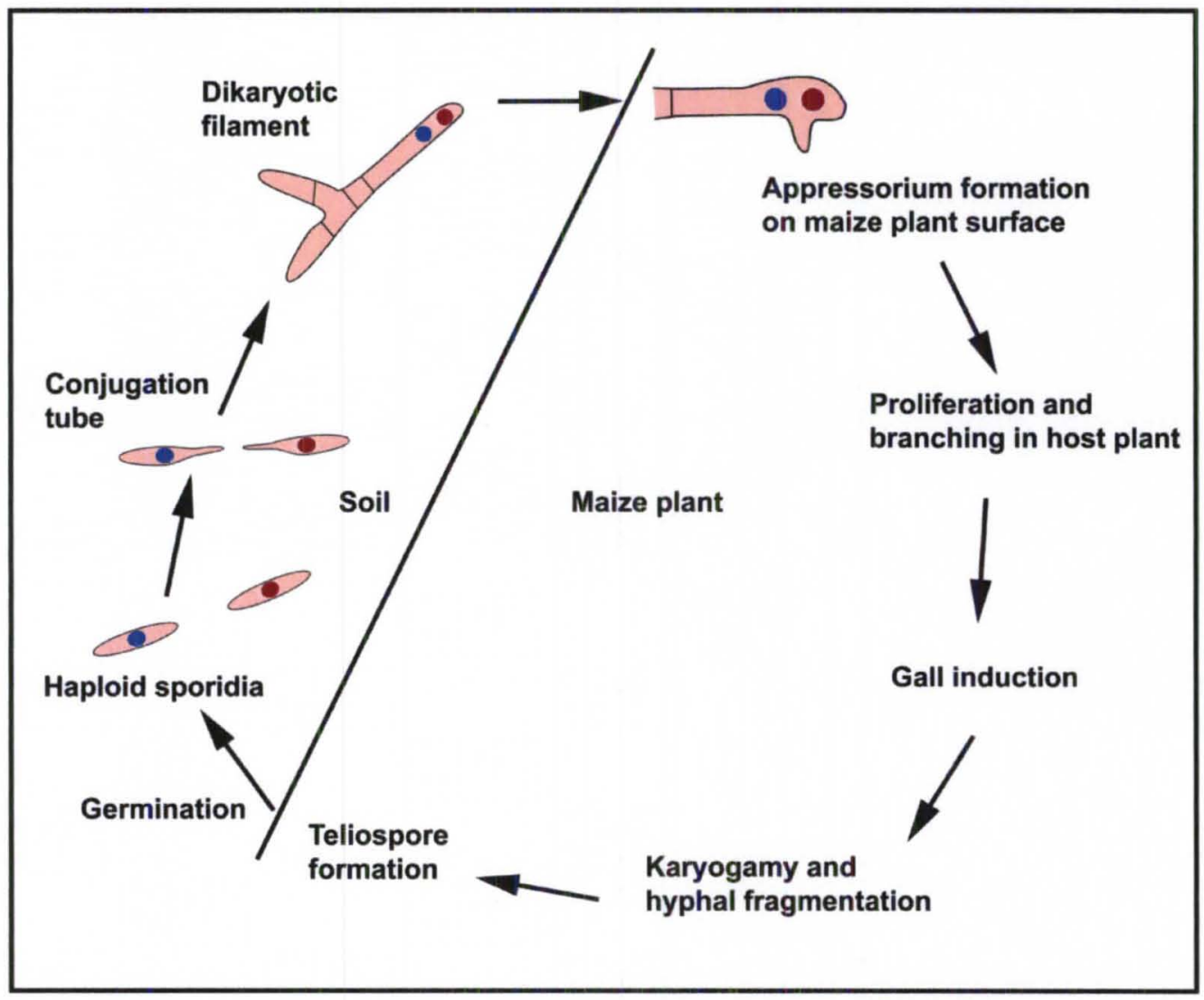

Figure 1: Life cycle of corn smut, Ustilago maydis

$U$. maydis secretes hydrolytic enzymes like pectate lyase to weaken plant cell wall in order to enter cells (Mueller et al., 2008). In contrast, some other pathogenic fungi like Collectotrichum graminicola (pathogen of corn and wheat) or Magnaporthe grisea (pathogen of rice) exert high turgor pressure to gain entry into host plant tissues (Kahmann and Kämper, 2004). The invasion is well controlled not to kill host cells. Only cell wall is weakened and the plasma membrane remains intact. Dikaryotic filaments multiply inside host tissues both 
intercellularly and intracellularly. Galls are formed as a result of modifying host tissues. In these galls, dikaryotic filaments undergo karyogamy to produce teliospores. Certain cues from the host plant are needed for formation of teliospores as under invitro conditions teliospores are not produced. When dry galls rupture, melanized teliospores are released in to the environment. Under favorable conditions, they produce pro-mycelium and undergo meiosis during germination. Haploid basidiospores are produced on basidium and are dispersed later (Klosterman et al., 2007).

\section{MATING TYPES IN USTILAGO MAYDIS}

Genetic information of U. maydis is organized on 23 chromosomes (MIPS Ustilago maydis database). Mating type is determined by two unlinked loci "a" and " $b$ " which are present on separate chromosomes. The 'a' mating locus is present on Chromosome 1 and exists as two idiomorphs a1 and a2. Both the idiomorphs encode precursors of specific lipo-peptide mating pheromone a (Mfa), G-protein coupled seven trans-membrane domain pheromone receptor a

(Pra) (Figure 2) and Right Border a protein (Rba). The function of the Rba protein has yet to be confirmed, but it seems to localize in the inner mitochondrial membrane (Schirawski et al., 2005). Rba has two membrane spanning domains (MUM Database) and has conserved domain similar to UbiA prenyltransferase superfamily (NCBI CD search). In E.coli, an enzyme 4-hydroxybenzoic acid oligoprenyltransferase, which belongs to UbiA family, is important for ubiquinone production. Ubiquinone is electron carrier in both prokaryotes and eukaryotes (Brauer et al., 2008). 


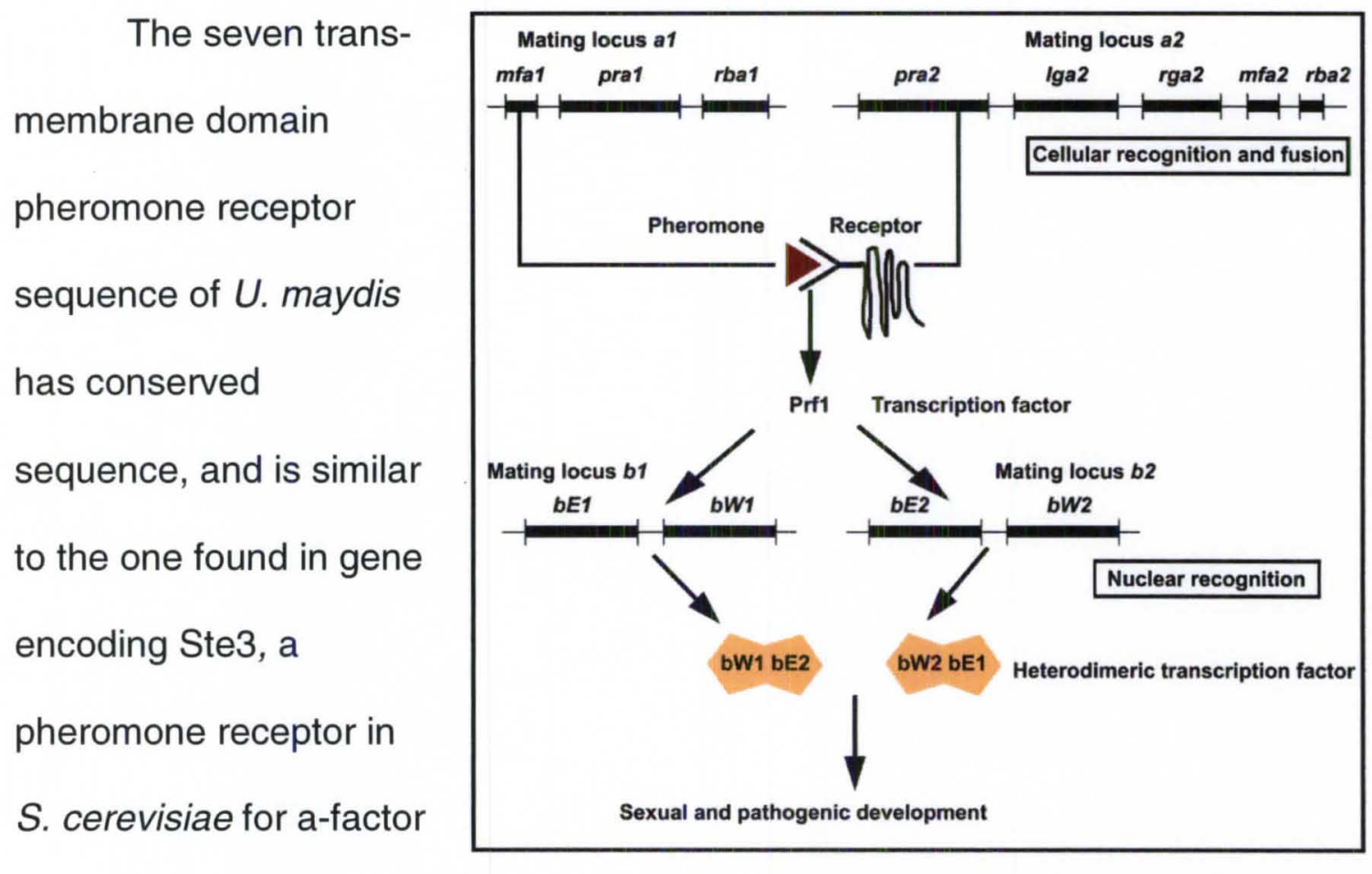

pheromone and $\mathrm{M}$ -

Figure 2: Interactions between the two mating-type loci during development of $U$. maydis. Adapted from (Bolker, 2001).

factor receptor in

Schizosaccharomyces pombe (Banuett, 1995). Haploid cells with mating locus

a1 will produce a1 specific pheromone and a trans-membrane receptor for a2

specific pheromone. Whereas, a haploid cell with mating locus a2 will produce a2 specific pheromone and a trans-membrane receptor for a1 specific pheromone.

Mating locus 'a' also regulates filamentation (Banuett and Herskowitz, 1989).

Pheromones are produced at a basal level in haploid cells and expression is upregulated when presence of an opposite mating type is sensed. The upregulation of pheromone expression results in cell cycle arrest (Garcia-Muse et al., 2004). Idiomorphic a2 has two additional ORFs Iga2 and rga2 which encode small mitochondrial proteins. In a dikaryotic filament, Lga2 promotes degradation of a1 mtDNA whereas Rga2 protects a2 mtDNA from degradation triggered by 
Lga2 and promotes inheritance of $a_{2}$ mtDNA in offspring. Interestingly, when $\mathrm{Rga} 2$ is deleted from $a_{2}$ mating type then, $a 2 \mathrm{mtDNA}$ is degraded as expected but, a1 mtDNA is not degraded and mitotypes of the offspring are a1 (Fedler et al., 2009).

Mating locus ' $b$ ' is present on Chromosome 5. Locus $b$ is multiallelic and has more than 25 forms. It encodes two homeodomain proteins bE and bW, which form a heterodimeric transcriptional factor. The amino acid sequence of both $\mathrm{bE}$ and bW each has a conserved region which contains a homeodomain motif and a variable $\mathrm{N}$-terminal region which is allele specific. Formation of functional bE-bW transcription factor acts as a positive feedback for Iga2 expression. Mating locus a, being involved in production and sensing of mating pheromones, is responsible only for fusion of cells. Cells with different mating locus a forms (i.e., a1 and a2) will fuse but further events like formation of stable dikaryon, and filamentation depend on mating locus $b$. A functional heterodimeric transcriptional factor is formed only when bE and bW proteins come from different mating types (for example bE1-bW2 or bE1-bW4). Mating locus $b$ itself recognizes self and non-self forms (Bolker, 2001). A functional transcription factor, bE-bW can trigger expression of more than 246 genes (e.g., Kpp6, the encode a MAP kinase) that results in downstream effects involved in pathogenicity (Kahmann and Kämper, 2004).

Mating types in fungi may or may not be stable. In the case of yeast, cells keep changing their mating types after every alternate generation. The two mating types in yeast are MATa and MATa (Strathern et al., 1982). In the case of 
U. maydis, the cells have stable well defined mating types. Switching like yeast is not observed. Moreover, in U. maydis after cellular fusion, the mating loci a genes are continually expressed as they are important for meiosis and sporulation process. In contrast, in S. cerevisiae, expression of pheromone and pheromone receptor genes stop completely after cell fusion (Banuett, 1995).

In order to fuse cells, the mating locus a needs to be expressed, and activation of mating locus $a$ is dependent upon signal transduction through the conserved MAPK pathway. In U. maydis, serine/threonine, p21 activated kinases (PAK) like Smu1 and Cla4 are involved in signaling as well. Smu1 affects expression of $m f a$ whereas, $\mathrm{Cla} 4$ is involved in cytokinesis. As a result of the MAPK cascade, a pheromone response factor, Prf1, is activated; this is a nuclear transcription factor. Prf1 can also be activated by another conserved signaling pathway which is the protein kinase $A(P K A)$ pathway. A very important component of these and other signaling pathways are GTP-binding proteins.

\section{G-PROTEINS AND SMALL GTP-BINDING PROTEINS}

Some $\mathrm{G}$ proteins are heterotrimeric and are composed of $\mathrm{G}$ protein $\alpha, \mathrm{G}$ protein $\beta$ and $G$ protein $y$, whereas, small G-proteins are monomer proteins. Both heterotrimeric $G$ proteins and small G- proteins coordinate biological processes and act as bio-timers. In eukaryotes, there are five conserved small G-proteins, for example, Ras, Rho, Rab, Sar1/Arf, and Ran family proteins. Proteins belonging to Ras family regulate gene expression whereas Rho family proteins are involved in cytoskeleton reorganization and gene expression. Rab and 
Sar1/Arf proteins are involved in vesicle trafficking and Ran proteins control transport in between nucleus and cytoplasm along with microtubule organization. These proteins act as molecular switches by turning themselves 'OFF' or 'ON', in presence of appropriate signal. The inactive form is bound to GDP, whereas active form is bound to GTP. In presence of appropriate signal, the Guanine Exchange Protein/Factor (GEF) aids the physical exchange of GDP with GTP to activate G-protein and small G-proteins. GDP Dissociation Inhibitor proteins (GDI) are also present in cells, in order to have tight regulation and to prevent mistakes. Once G-proteins and small G-proteins are activated, their intrinsic GTPase activity is turned 'ON', by GTPase Activating Protein (GAP) leading to hydrolysis of GTP to GDP. This hydrolysis turns 'OFF' both $G$ and small Gproteins (Takai et al., 2001).

The Ras and Rho family proteins work in co-ordination with each other. To relay a signal effectively many small G-proteins might be involved. For instance, bud formation in S. cerevisiae involves activation of a Ras family protein called Rsr1 through yet to be known cues. GTP-Rsr1 binds to a GEF Cdc24. Activated Cdc24 binds and activates Cdc42 (a Rho family small G-protein) by replacing GDP with GTP. Activated Cdc42 helps in actin reorganization and relays the signal to downstream Rho1 and Sec4 (a Rab family) proteins. Rho1 triggers cell wall synthesis and Sec4 is involved in vesicle trafficking (Takai et al., 2001).

In eukaryotes, to perceive a signal from environment, the cell surface has receptors and if these receptors are associated with G or small G-proteins, then these surface receptors are known as G-Protein Coupled Receptors (GPCR). 
GPCR transduce signals for various cellular responses, such as peptide hormone, taste, odor, vision, chemokines and neurotransmitters (Lefkowitz, 2004). A characteristic feature of GPCR is that they have seven transmembrane domains with a ligand binding domain outside the cell and tail bound to heterotrimeric G-protein. Regions inside the cell cytoplasm have multiple phosphorylation sites. Upon activation through ligand binding, the GPCR needs to be turned OFF which can be achieved either by internal GTPase activity of Gproteins or by ubiquitination followed by endocytosis. For example, pheromone receptor, Ste2p, in S. cerevisiae is a GPCR and upon activation by $\alpha$-factor, its cytoplasmic tail is hyperphosphorylated and the receptor is endocytosed to be recycled (Hicke et al., 1998). An additional regulation is mediated by a regulator Sst2. sst2 expression is up-regulated by pheromone sensing and it acts as a negative feedback by activating intrinsic GTPase activity of Gpa (Ballon et al., 2006).

\section{MITOGEN-ACTIVATED PROTEIN KINASE (MAPK) PATHWAY}

MAPK pathways are involved in cell division, growth and differentiation, and stress responses. MAPK cascade is conserved among eukaryotes including humans. The core model of MAPK cascade has three serine/threonine kinases. Upon activation through upstream signals the first kinase MEKK/MAPKKK is activated which in turn phosphorylates and activates the second kinase which is MEK/MAPKK. MEK/MAPK further phosphorylates and activates the third kinase in the cascade which is MAPK. The activity of these kinases is regulated by phosphatases. In yeast there are three fully understood MAPK cascades, which 
are triggered under different environmental signals like pheromone sensing, osmotic stress or other signals for filamentation (Figure 3). The kinases in the cascade have multiple phosphorylation sites, which determine the downstream target. Sometimes, scaffolding proteins help in concentrating players in a particular response to avoid multiple outcomes. For example, Ste5 is a scaffolding protein in pheromone response MAPK in yeast and tethers Ste11 (MEKK), Ste7 (MEK) and Fus3/Kss1 (MAPK). The upstream signal for this cascade comes from a/a factor binding to Ste3/2 GPCR receptor, respectively, depending on the mating type. Gpa1 subunit of heterotrimeric G-protein dissociates from the complex and activates Ste20, a PAK Kinase. Ste20 activates Ste11 (MEKK). The Fus3/Kss1 MAPK regulates function of Dig1/2 in negative manner in order to activate Ste12, a nuclear transcription factor, which in turn expresses mating specific genes.

Fus3/Kss1 also activates Far1, another transcriptional factor, which mediates cell

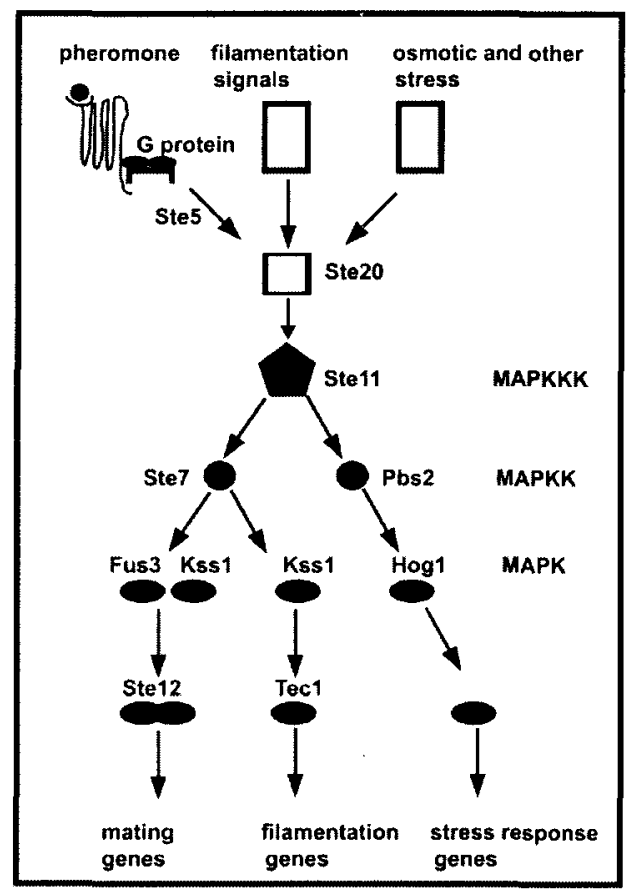

Figure 3: S. cerevisiae, three MAPK cascades and their shared components. Adapted from (Bradwell, 2006).

cycle arrest. And under high osmotically stressed conditions, the stress response genes are expressed through a sequential phosphorylation event involving Ste20, Ste11 (MEKK), Pbs2 (MEK), and Hog1 (MAPK). On the other hand, when different signals, for filamentation, are sensed then filamentation genes are 
expressed via activation of Ste20, Ste11, Ste7, Kss1, and Tec1. The mediator Ste20 is common in all the routes, yet all the cascades remain isolated from each other through unknown mechanisms. Ste20 has a CRIB (Cdc42/Rac Interactive Binding) domain. Cdc42 is a small monomeric Rho-like G-protein, which is activated by Cdc24 (GEF). Cdc42 interacts with Ste20 to turn it 'ON' (Lamson et al., 2002). Only a few of the mechanisms are known that explain isolation of the different cascades from each other, for example, Kss1 is shared in both pheromone response and filamentation cascade, yet the outcomes are different under different conditions. There is a highly controlled mechanism involved. In the pheromone response pathway, Fus3 is also expressed along with Kss1. The Fus3 serves two roles: 1) It phosphorylates Tec1 resulting in ubiquitinylation and degradation. 2) It regulates the time of Kss 1 being active. Fus3 activates an unknown upstream player that dephosphorylates Kss1. In absence of Fus3, Kss1 activates Tec1 and results in the filamentation response. Other regulatory mechanisms, such as what controls expression of Fus 3 along with Kss1 are not yet known (Bardwell, 2006).

In U. maydis, the MAPK cascade involved in the pheromone response pathway is similar to yeast MAPK cascade, but all the connections still need to be worked out (Figure 4). The pheromone secreted from opposite mating type is sensed by GPCR; Pra1/2. The Gpa dissociates from heterotrimeric G-protein and activates Ras2, a small G protein. Other players like Cdc42 and Smu1 also get involved in relaying the signal, but the exact mechanism is yet unknown. Smu1 
(Ste20 affecting mating in Ustilago), is a PAK-like kinase and is a homologue of Ste20 of yeast. In the absence of Smu1, mating is attenuated.

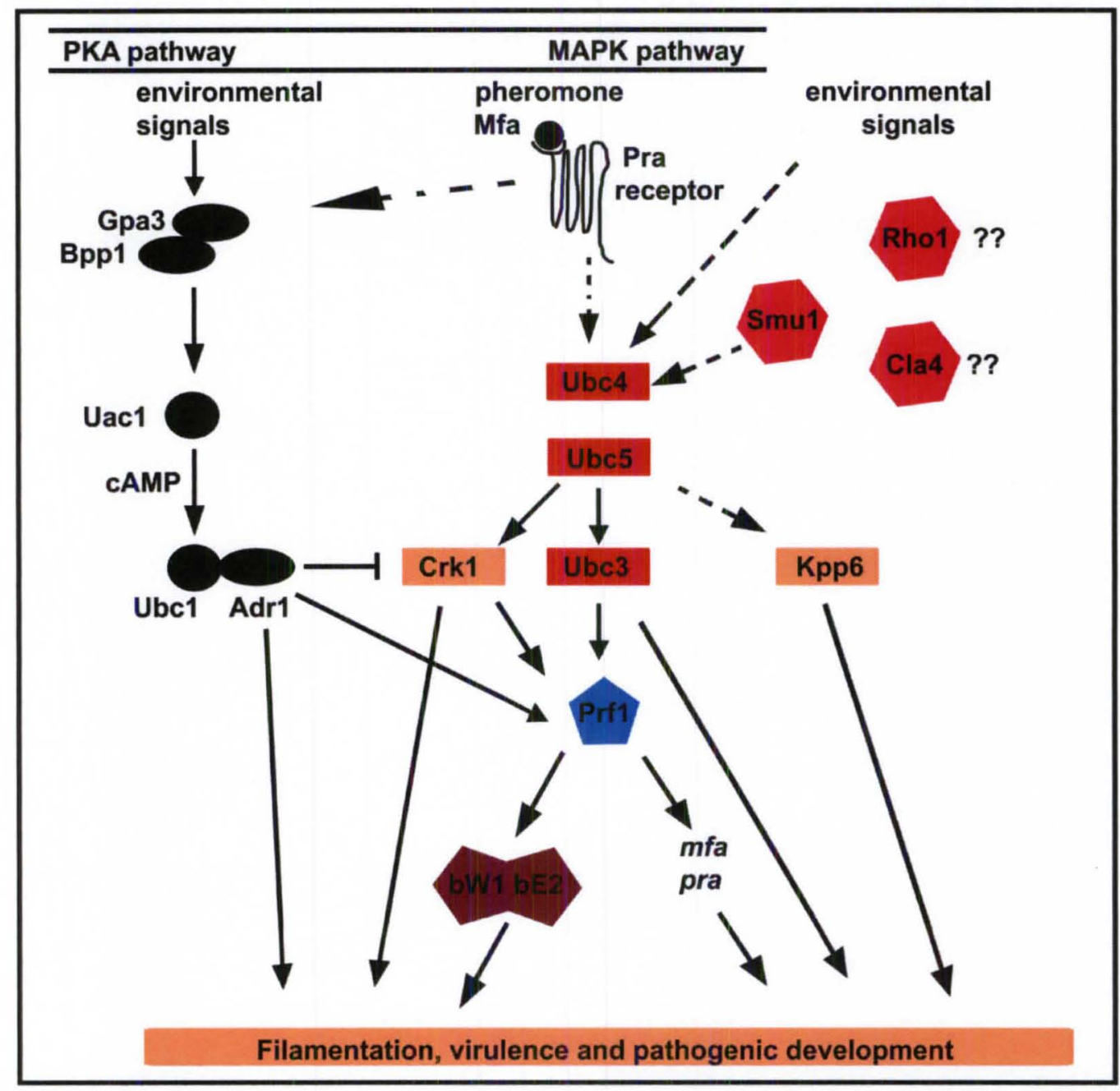

Figure 4: U. maydi,s, PKA pathway (Protein kinase A) on left and MAPK pathway (Mitogen activated pathway) on right. Adapted from (Kahmann and Kamper, 2004).

The core cascade in the case of U. maydis includes Ubc4/Kpp4 (MAPKKK), Ubc5/Fuz7 (MAPKK), and Ubc3/Kpp2 (MAPK). Ubc2 serves as a scaffolding protein. Ubc stands for Ustilago Bypass of Cyclase. The pathway activates Crk1 and Prf1, the transcription factors, by phosphorylating them at various positions. Crk1 and Prf1 (Pheromone Response Factor) plays important role in inducing mating loci: $m f a 1 / 2$, pra1/2 and $b$ locus genes. When Prf1 is 
phosphorylated via MAPK pathway then, only, $b$-dependent genes are activated. In addition, various downstream functions are regulated, such as: cell cycle, cell fusion, and formation of conjugation tube, appressorium formation, and filamentation. There is a second MAPK, Kpp6, which is involved in penetrating plant tissue. Also, the players of MAPK pathways could be activated by other environmental or host cues (Kahmann and Kämper, 2004) (Nadal et al., 2008).

\section{PROTEIN KINASE A (PKA) PATHWAY}

In Ustilago maydis, in addition to MAPK pathway, phosphorylation of the transcription factor, Prf1, can also be mediated through another conserved protein Kinase A pathway. This PKA pathway, which is a cAMP-dependent kinase pathway, also contributes in the activation of both mating loci, $a$ and $b$. Both MAPK and PKA pathways co-ordinate to have an optimized outcome, depending upon signal. Hyper-activation of PKA results in a multiple budding phenotype, whereas down-regulation of PKA pathway results in filamentous phenotype (Gold et al., 1997). These outcomes are opposite to what is observed in yeast, when PKA is either up-regulated or down-regulated (discussed later). The GPCR and G-proteins involved in this pathway are activated by sensing signals from host plant, but the mechanism is still unclear. The core unit in the PKA pathway consists of two catalytic subunits bound to two regulatory subunits. And activity of the catalytic subunits is de-repressed via cAMP binding to regulatory subunits. The levels of CAMP are regulated by phosphodiesterases. In $U$. maydis, there are two well studies umpde1/2 genes that control levels of cAMP and therefore activity of PKA pathway (Agarwal et al., 2010). Upon 
sensing a signal through GPCR, the Gpa3 subunit of the heterotrimeric G-protein dissociates and activates the Uac1 (Ustilago Adenylate Cyclase) enzyme. Uac1 converts available ATP into CAMP. cAMP binds to the regulatory subunits named Ubc1 (Ustilago Bypass Cyclase1) to alter their conformation in a way that causes Ubc1 to release catalytic subunits Adr1/Uka1. Release of catalytic subunits makes them active and thereby, activates the PKA pathway. Active catalytic subunits: a) phosphorylate Crk1 to regulate its function in a negative manner, $b$ ) phosphorylate Prf1 to activate it (Kahmann and Kämper, 2004).

In yeast, the signals come mainly from nutrient sensing, such as availability of

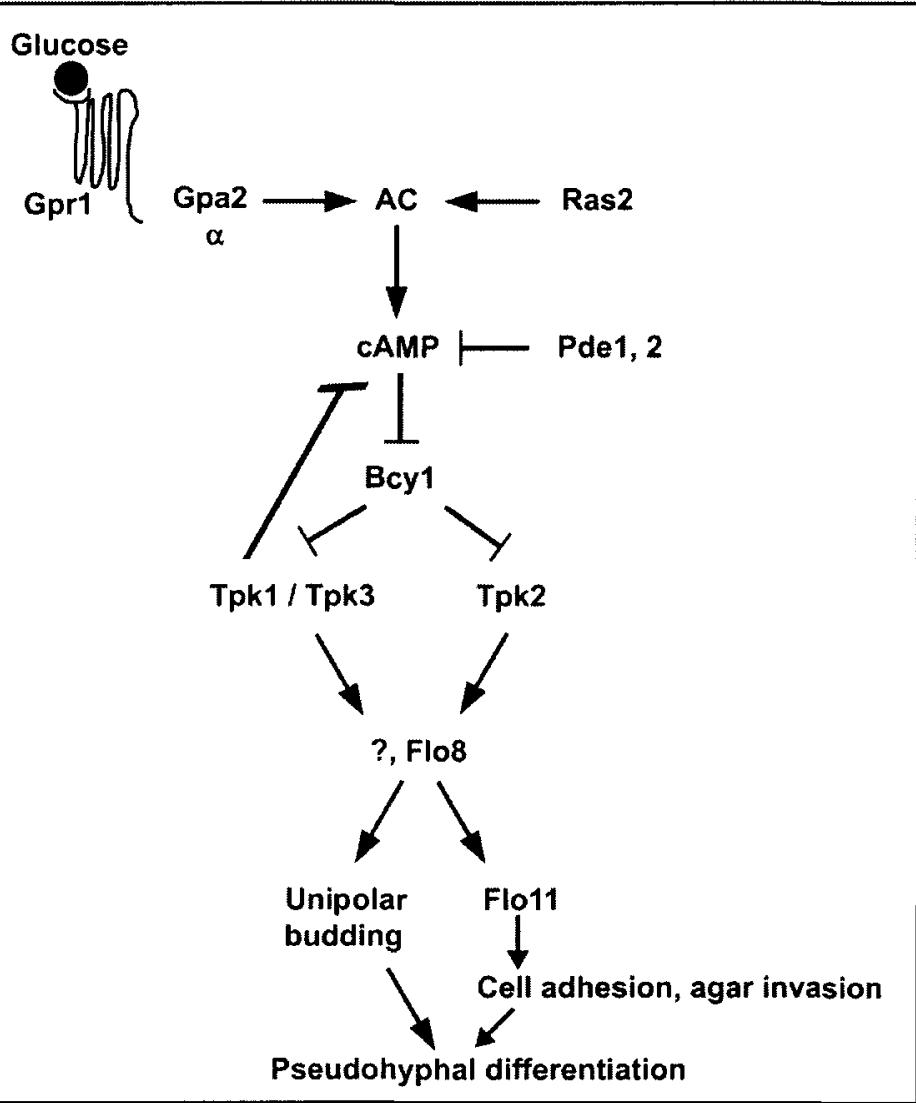

Figure 5: S. cerevisiae. Signal transduction cascade: PKA (protein kinase A) pathway regulating pseudohyphal differentiation Adapted from (Lengeler et al., 2000).

fermentable carbon and low nitrogen (Figure 5). Upon activation, Gpa2 activates AC (adenylate cyclase) enzyme. The enzyme is also acted upon by another small G-protein, Ras2. AC converts ATP into CAMP. CAMP binds to both the regulatory subunits Bcy 1 and alters their configuration, due to which catalytic 
subunits are released and become active. In yeast there are three different types of catalytic subunits present, Tpk1, Tpk2 and Tpk3. All these three catalytic subunits share a redundant function. A triple mutant for these three genes is not viable. When Tpk2 is active, it results in cell adhesion and pseudohyphal growth via activation of Flo8 and Flo11. But Tpk1/Tpk3 negatively regulates levels of cAMP and thereby does not promote filamentous growth (Lengeler et al., 2000).

Proteins mentioned in the following sections either are important players in the above mentioned conserved pathways or, they interact with members of the pathways, and affect mating, colony morphology, cell morphology, and virulence and pathogenicity. The proteins are the PAK like kinases: Smu1 and Cla4, a putative arginine methyltransferase, Hsl7, and Rho, small GTPase.

\section{SMU1: STE20-LIKE PROTEIN KINASE WITH AN EFFECT ON USTILAGO MATING}

In U. maydis, Smu1 is a homologue of the PAK kinase of yeast, Ste20. Ste20 interacts with Cdc42 and a p21 GTPase of RAS super-family. As mentioned earlier, it is one of the important players of the MAPK pathway and is required during cell cycle as it regulates organization of actin and cell polarity (Holly and Blumer, 1999). The, smu1 gene (um12272) is located on

Chromosome 13 of the $U$. maydis genome and codes for a protein which is 826 amino acids in length (MIPS Ustilago maydis database (MUMDB), http://mips.helmholtz-muenchen.de/genre/proj/ustilago). Like Ste20, the Nterminal portion of the Smu1 protein also has a CRIB domain and the C-terminal 
portion has catalytic/kinase domain. Smu1 plays an important role in the MAPK pathway; it is involved in the pheromone response pathway and filamentation, cell morphogenesis, cytokinesis, and plant pathogenicity. If $s m u 1$ is deleted or disrupted, the mating ability of $U$. maydis is reduced, and the extent of reduction in mating is dependent upon the type of mating background. Reduction in mating, as observed on YPD-charcoal agar plate, was more pronounced in an a2b2 background as compared to the a1b1 background, when the smu1 mutants were each allowed to mate with compatible opposite mating type wild type (WT). In addition, the mating reaction was reduced greatly when both the compatible mating partners were defective in the smu1 gene (Smith et al., 2004). Also, pathogenicity on corn plants was reduced. Smu1 was observed to up-regulate expression of the $m f a 2$ gene to a greater extent than the $m f a 1$ gene. Overexpression of smu1, led to a slight increase in mating reaction, but only in an $a 1 b 1$ background, whereas over-expression in the $a 2 b 2$ background displayed reduction in mating as compared to WT mating reaction. Under low ammonium conditions, smu1 disrupted a2b2 strains exhibited colonies with less filamentation as compared to their respective $\mathrm{WT}$, and over-expressed smu1 strains produced a more filamentous colony morphology in the $a 1 b 1$ mating type as compared to their respective WT (Smith et al., 2004). Also, cell length varies in smu1 mutant strains in a mating-type background dependent fashion. The $\Delta s m u 1$ mutant showed significant decreases in cell length in a2b2 backgrounds as compared to respective WT, whereas, over-expression strains had increases in cell length that were significant only in the a1b1 mating background (Lovely et al., 2011). 


\section{CLA4: PAK-LIKE KINASE}

Cla4 is another PAK-like kinase. In yeast it is involved in cell polarity, septum formation, cytokinesis, pheromone response, and vacuole inheritance. Like Ste20, Cla4 is also activated by the small G-protein Cdc42. In addition to similar functional and interactive domains as Ste20, Cla4 possesses a $\mathrm{PH}$ (Pleckstrin homology) domain. PH domains help in attachment to the plasma membrane phosphoinositides (Takahashi and Pryciak, 2007). Both Cla4 and Ste20 have many redundant functions along with their unique roles. A double mutant of Ste20 and Cla4 is not viable (Keniry and Sprague, 2003). Cla4 may be required in the pheromone response pathway by interacting with $\mathrm{Cdc} 42$ and facilitating function of Ste20 (Benton et al., 1997). Studies have shown that if a single amino acid is changed in Cla4, it can acquire functions of Ste20 without losing its own functions (Keniry and Sprague, 2003). In U. maydis, cla4 (um10145) is present on chromosome 5 and codes for a 684 amino acid long protein (MUMDB). Similar to yeast, in $U$. maydis, Cla4 is required for proper budding, cell polarity, filamentation. Partial deletion strains with the CRIB domain disrupted are not viable due to hyperactive Cla4 kinase. Cells with a complete deletion of cla 4 were highly branched and divided by central contraction at septal cross walls instead of normal budding. This may be due to delocalized deposition of chitin during budding. The $\Delta c l a 4$ mutants stained with calcofluor white showed that the septum was present in between hyphal cells, indicating that Cla4 is not required for proper localization of $1,3-\beta$-glucan. Calcofluor dye stains $1,3-\beta-$ glucan which is a main constituent of fungal cell wall. Wheat germ agglutinin 
(WGA) is another fluorescent dye that binds to chitin polymer. Cells labeled with WGA revealed that chitin in such mutants did not localize at the place of division or bud neck, but instead localized uniformly throughout the cell wall. In yeast, it is known that activity of the enzyme 1,3- $\beta$-D-glucan synthase is interrupted if the small GTPase, Rho1, is not present (Mazur and Baginsky, 1996). The small GTPase, Rho1, is discussed later. Like smu1 disrupted strains, cla4 deleted strains also exhibit phenotypes specific to the particular mating type background. The cla4 mutant showed a significant reduction in mating and pathogenicity, but in the $a 1 b 1$ background only; in a mating reaction between a $1 b 1 \Delta c / a 4$ and a2b2WT on potato dextrose agar with activated charcoal there was a significant reduction. The mating reaction was reduced greatly between compatible partners if both are $\Delta c l a 4$ mutants. The cell morphology was also altered in $\Delta c l a 4$ strains, depending on the background of the strain. The a1b1 $\Delta$ cla 4 cells possessed septate branched hyphae and aggregated when grown in the liquid rich media, whereas, $a 2 b 2 \Delta c l a 4$ cells divided by contraction at centrally placed cross wall. In another mating background BUB8 ( $a 2 b 4)$ such deletion strains showed single nucleate branched elongated hyphae, which was more similar to a1b1 $\Delta c l a 4$ cells (Leveleki et al., 2004).

\section{HSL7: A PUTATIVE ARGININE N-METHYLTRANSFERASE AND AN INTERACTOR OF SMU1}

The $h s / 7$ gene, also known as um 15057 , is present on chromosome 2 and codes for a 765 amino acid protein (MUMDB). Earlier studies have shown that homologues of $\mathrm{Hsl} 7$ interact with Ste20 and other PAK-like kinases. Hsl7 is 
involved in response to environmental conditions, morphology of the cell and cell cycle regulation. In yeast, it promotes mitotic division through $\mathrm{G}_{2} / \mathrm{M}$ transition by helping in degradation of an inhibitor, Swe1. It has also been published that Hsl7 has an opposing affect upon filamentation as compared to Ste20. Hsl7 may be accomplishing this task by regulating Cdc42, which is an activator of Ste20 (Fujita et al., 1999). In U. maydis, $\Delta h s / 7$ mutants were observed to have a significant increase in cell length as compared to their respective WTs, but this did not depend upon the mating background. Over-expression of $h s / 7$ caused a significant decrease in cell length but only in a2b2 mating background. Under low ammonium conditions, an over-expression strain, hs/7Otef, displayed a slight decrease in filamentous colony morphology, but also only in the a $2 b 2$ mating background. Hsl7 did not affect mating in any way. Outcomes of both Smu1 and Hs17 mutants were opposite to each other and results from Yeast-two hybrid analysis revealed that Hsl7 interacts with Smu1. (Lovely et al., 2011)

\section{RHO1: A SMALL GTPASE AND AN INTERACTOR OF SMU1}

As mentioned earlier, in order to undergo changes in cellular morphology, the cell wall needs to be modified. A Rho family GTPase is involved in the process. Rho (Ras homologue) belongs to the Ras super-family and includes the small GTPase Cdc42, Rho, and Rac. Rho GTPases possess two domains. One is the $\mathrm{PH}$ (pleckstrin homology) domain which is required for membrane attachment through phosphoinositides and another is $\mathrm{DH}(\mathrm{Dbl})$ domain which is actually a catalytic Rho-GEF domain (Ozaki et al., 1996). Rho1 proteins help in recruitment of the required protein complexes at the Polar Regions of cells. Post 
recruitment these protein complexes reorganize actin cytoskeleton, by which cell wall modifying enzymes, cell wall building material like $1,3-\beta$-glucan and chitin are delivered to the growing tip (Carbo and Perez-Martin, 2008). I have already mentioned that small G-proteins require a GEF to activate them by exchanging GDP with GTP. In S. cerevisiae, Cdc24 is GEF for Cdc42, whereas, in $U$. maydis, Don1 is GEF for Cdc42 and Cdc24 is GEF for both Rho1 and Rac1 (Pham et al., 2009) (Weinzierl et al., 2002). In U. maydis, rho1 (um05734) is present on chromosome 16 and encodes a 194 amino acid protein (MUMDB). Earlier yeast two hybrid studies revealed that Rho1 interacts with $S m u 1$. In $U$. maydis, Rho1 seems to play a role in cell viability, as deletion of rho1 was not possible. Over-expression of Rho1 exhibits mating background specific effects on the mating reaction. Mating seems to be reduced in rho1 over-expressed strains. Mating is reduced to a greater extent when the strain over-expressing rho1 was a2b2 and was mated with the $a_{1} b_{1}$ WT (Pham et al., 2009) (Lovely et. al.; presented at $26^{\text {th }}$ Fungal Genetics Meetings Asilomar CA, March 2011).

\section{INITIAL RESEARCH INTEREST OF THESIS}

The fungus $U$. maydis requires a pathogenic stage in corn plants, in order to complete its sexual life cycle. The signaling pathways involved are conserved among most of the eukaryotes, including humans. As mentioned earlier, if the expression levels of players in the conserved pathways are altered, either disrupted or over-expressed, then $U$. maydis cells experience defects in several ways which include altered mating behavior, altered colony morphology, and abnormal cell morphology. Virulence and pathogenicity may also be affected due 
to such gene alterations. As an example, strains disrupted for Smu1 exhibit reduction in mating and pathogenicity which is more pronounced in a $2 b 2$ mating background. Also cells respond in a mating background dependent manner to low ammonium conditions: $\Delta s m u 1 a 1 b 1$ is less filamentous as compared to a1b1WT. The a $2 b 2$ colony where smu 1 is over-expressed is more filamentous when compared to a2b2WT colony (Smith et al., 2004). Similarly, mutants of another PAK, Cla4 also behave differently depending upon mating type background. On SLAD media (low ammonium media) $\triangle$ cla4a1b1 colonies showed a dramatic increase in filamentation ability as compared to a1b1WT. In contrast, $\triangle c l a 4 a 2 b 2$ colonies are much smaller and less filamentous as compared to $a 2 b 2 \mathrm{WT}$. In addition, their cell morphology seems to be affected: $\Delta c l a 4 a 1 b 1$ cells are quite elongated, branched, and have a tendency to clump together, whereas, $\Delta c l a 4 a 2 b 2$ cells undergo fission at a central cross wall. Reduction in mating and pathogenicity is also reported which is again prominent in the $\Delta c / a 4 a 1 b 1$ mating background. The mating dependent trend is also observed in the rho1 GTPase over-expression strain, with greater reduction in mating in $a 2 b 2$ mating background.

From the combination of examples described above, it appeared that mating type background, either the particular a locus or the allele type at the $b$ locus, might have an effect in regulating components of signaling pathways. Thus, in this thesis, I intended to study which mating locus was involved for the above mentioned behavioral changes associated with either gene disruptions or gene over-expression. I endeavored to identify which aspect(s) of mating-type 
background were responsible for this apparent behavior. Alternatively, my investigations may point to other unidentified loci in the background that contribute to or control these phenotypes. 


\section{CHAPTER II}

\section{SPECIFIC b ALLELES MATTER IN PHYTOPATHOGENIC USTILAGO MAYDIS INTRODUCTION}

The corn smut fungus, Ustilago maydis is a basidiomycete and serves as a model organism to study host-pathogen interactions. Also, genetic processes like DNA recombination, and repair were studied originally in U. maydis (Holliday, 2004). The fungus reproduces by both asexual and sexual means. The selfsterile fungus requires compatible mating basidiospores to undergo sexual reproduction. The fungus must infect its host plant, maize (corn) in order to complete its sexual life cycle. To do so, haploid cigar shaped basidiospores known as sporidia, must first mate. After cytoplasmic fusion, cells undergo a dimorphic switch to a filamentous form and become infectious. Certain cues from the host plant are also involved in infectious hyphal development (Klosterman et al., 2007). A similar dimorphic switch is observed in other human pathogenic fungi such as Candida albicans, Histoplasma capsulatum, and Blastomyces dermatitidis. The infectious form in C. albicans is filamentous whereas, in $\mathrm{H}$. capsulatum and $B$. dermatitidis it is yeast like budding form 
(Nadal et al., 2008). Ustilago cells also filament in response to environmental conditions such as low nitrogen, low pH and exposure to lipids (Klose et al., 2004).

The dimorphic switch under low nitrogen conditions is also observed in $S$. cerevisiae (Nadal et al., 2008). Fungal cell walls are composed of $60 \%$ of $1,3-\beta-$ glucan, $40 \%$ of mannoproteins, and about $1 \%$ of chitin. So, for a fungal cell to undergo dimorphic switch, it has to reorganize its cytoskeleton and modify components of cell wall in a highly regulated manner. Various genes are involved that aid in such a transition, especially genes that encode small GTP-binding proteins and G-proteins. These genes are involved in conserved signaling pathways like the Mitogen-Activated Protein Kinase (MAPK) and Protein Kinase A (PKA) pathway. These signaling pathways are conserved among most of the eukaryotes, including humans and are well studied in yeast. (Garcia-Pedrajas et al., 2008).

In U. maydis, the mating type is determined by two unlinked loci: the mating locus ' $a$ ' and the mating locus ' $b$ '. The ' $a$ ' mating locus exists as two idiomorphs $a 1$ and a2. Both the idiomorphs encode precursors of specific lipopeptide mating pheromone a (Mfa), G-protein coupled seven trans-membrane domain pheromone receptor a (Pra) and Right Border a protein (Rba) (http://mips.helmholtz-muenchen.de/genre/proj/ustilago). The function of the Rba protein has yet to be confirmed, but it seems to localize in the inner mitochondrial membrane (Schirawski et al., 2005). Idiomorphic a2 has two additional ORFs Iga2 and rga2 which encode small mitochondrial proteins and promote 
inheritance of a2 mtDNA in offspring (Fedler et al., 2009). The mating locus $b$ is multiallelic and has more than 25 forms. It encodes two homeodomain proteins $\mathrm{bE}$ and $\mathrm{bW}$, which form a heterodimeric transcriptional factor. Prior to this study, it was known that a functional heterodimeric transcriptional factor is formed only when $\mathrm{bE}$ and $\mathrm{bW}$ proteins come from different mating types. In mated cells, a functional nuclear transcription factor, bE-bW can trigger up-regulation of more than 246 genes (e.g.; the MAP kinase Kpp6) that results in downstream effects involved in pathogenicity (Kahmann and Kämper, 2004).

Activation of mating locus $a$ is dependent upon signal transduction through the conserved MAPK pathway. In U. maydis, a serine/threonine, p21 activated kinases (PAK) Smu1 is involved in signaling. Smu1 is a homologue of the PAK kinase of yeast, Ste20 and affects expression of $m f a$. Like Ste20, the $\mathrm{N}$-terminal portion of Smu1 protein has a CRIB domain and the C-terminal portion has catalytic/kinase domain. It is involved in the pheromone response pathway, filamentation, cell morphogenesis, cytokinesis, and plant pathogenicity. Cla4 is another PAK like Kinase and is involved in cell polarity, septum formation, cytokinesis, pheromone response, and vacuole inheritance. Both Ste20 and Cla4 have many redundant functions along with their unique roles, as evidenced by the fact that a double mutant of ste20 and cla 4 is not viable (Keniry and Sprague, 2003). A vital small GTPase Rho1, which belongs to Ras super-family, is an interactor of Smu1. Rho1 helps in recruitment of the required protein complexes at the polar regions of cells. Post recruitment these protein complexes reorganize actin cytoskeleton (Carbo and Perez-Martin, 2008). In U. maydis, disruption or 
over-expression of these genes results in defects in several ways which include altered mating behavior, altered colony morphology under low nitrogen, and abnormal cell morphology. Virulence and pathogenicity may also be affected due to such gene alterations.

Phenotypes associated with certain gene alterations are associated more with certain genetic backgrounds, apparently correlated with mating type. As observed on YPD medium with the activated charcoal plate mating assay, it was documented earlier that mating efficiency was reduced compared to WT in smu1 disrupted strains, even when only one of the mating partners had the disruption. This reduction was more pronounced when the lesion was in a $2 b 2$ background as compared to when it was found in the $a 1 b 1$ background. When one of the mating partners over-expressed smu1, mating efficiency was slightly increased as compared to WT mating pair when smu1 was over-expressed in an a1b1 background. Moreover, the smu1 disruption mutants exhibited reduction in disease indices for plant infection, again with a genetic effect when the disruption was in the a2b2 background (Smith et al., 2004). The $\Delta c l a 4$ mutants showed reduction in mating efficiency when the $\Delta c / a 4$ mutation was present in a1b1 genetic background. Also, a1b1 $\Delta$ cla4 mutant mated with a2b2WT was less pathogenic to corn plant as compared to WT mated pair (Leveleki et al., 2004). A similar behavior dependent on genetic background was reported for overexpression of rho1 in the $a 2 b 2$ genetic background when mated with $a 1 b 1 \mathrm{WT}$ (Pham et al., 2009). In addition to mating behavior, filamentation on low ammonium media for smu1 (Smith et al., 2004) and cla4 mutants (Lovely et al., 
2011) and cell morphology for $\Delta c / a 4$ mutants was also dependent upon genetic background (Leveleki et al., 2004). By observing the above mentioned behavior, it appears that mating type background, either the particular a locus or the allele type at the $b$ locus might have an effect in regulating components of signaling pathways.

\section{MATERIALS AND METHODS}

STRAINS AND GROWTH CONDITIONS: The strains of $U$. maydis used for present study are listed in Table 1 . The $U$. maydis strains were grown at $25^{\circ} \mathrm{C}$ in liquid or solid YEPS medium [1\% (w/v) yeast extract, $2 \%(\mathrm{w} / \mathrm{v})$ peptone, and $2 \%(w / v)$ sucrose or dextrose] (Fisher Scientific, Fair Lawn, NJ), solid YEPS had $1.5 \%(\mathrm{w} / \mathrm{v})$ agar and SLAD with $\mathrm{pH} 5.8[0.17 \%(\mathrm{w} / \mathrm{v})$ YNB (yeast nitrogen base without ammonium sulfate or amino acids) (Difco, Sparks, MD), $50 \mu \mathrm{M}$ ammonium sulfate, and $2 \%(\mathrm{w} / \mathrm{v})$ dextrose]. Solid SLAD was prepared by adding $2 \%(\mathrm{w} / \mathrm{v})$ agar (Hofmann et al., 2004). Plasmid based U. maydis mutants were maintained using appropriate drug in growth medium. Liquid cultures were grown with shaking at $260 \mathrm{rpm}$. Mating medium was prepared by adding $1 \%(\mathrm{w} / \mathrm{v})$ charcoal, activated (w/v) (Sigma Life Sciences, St. Louis, MO) to either YEPdextrose with $1.5 \%(\mathrm{w} / \mathrm{v})$ agar or PDA (potato dextrose agar) (Difco, Sparks, MD).

PRIMER DESIGN AND PCR: Primers were designed with the Primer3 program (http://frodo.wi.mit.edu/) and based on genome sequence available online at MUMDB (http://mips.helmholtz-muenchen.de/genre/proj/ustilago). All 
primers listed in Table 2 were obtained from Eurofins MWG Operon (Huntsville,

AL). PCR and gradient PCR were run on Eppendorf Mastercycler or a DNA

Engine peltier thermal cycler (Bio-Rad Laboratories, Hercules, CA, respectively).

A DNA template of $100 \mathrm{ng}$ and ExTaq DNA Polymerase (Clontech laboratories,

Inc.) was used for all PCR.

Table 1: Origin and genotypes of $U$. maydis strains

\begin{tabular}{|c|c|c|}
\hline Strains & Genotypes & References or source \\
\hline 10/18 $\Delta$ smu1 & $a 1 b 1 s m u 1:: c b x^{R}$ & (Smith et al., 2004) \\
\hline FB1 & $a 1 b 1$ & (Banuett and Herskowitz, 1989) \\
\hline FB2 & $a 2 b 2$ & (Banuett and Herskowitz, 1989) \\
\hline $\mathrm{FB} 1 \Delta s m u 1$ & $a 1 b 1 s m u 1 \Delta:: c b x^{R}$ & (Lovely et al., 2011) \\
\hline $\mathrm{FB} 2 \Delta s m u 1$ & $a 2 b 2 s m u 1 \Delta:: c b x^{R}$ & (Lovely et al., 2011) \\
\hline FB1smu1Otef & $a 1 b 1 \mathrm{P}_{\text {oter }}-\mathrm{Smu1}-\mathrm{cbx} \mathrm{x}^{R}$ & (Lovely et al., 2011) \\
\hline FB2smu1Otef & $a 2 b 2 \mathrm{P}_{\text {oter }}-s m u 1-c b x^{R}$ & (Lovely et al., 2011) \\
\hline $\mathrm{FB} 1 \Delta$ cla4 & $a 1 b 1$ cla $4 \Delta:$ hyg ${ }^{R}$ & (Leveleki et al., 2004) \\
\hline $\mathrm{FB} 2 \Delta \mathrm{cla} 4$ & $a 2 b 2 c l a 4 \Delta:: h_{y g}^{R}$ & (Leveleki et al., 2004) \\
\hline FB1cla4Otef & a1b1 $\mathrm{P}_{\text {otef }}-c / a 4-c b x^{R}$ & (Lovely et al., 2011) \\
\hline FB2cla4Otef & $a 2 b 2 \mathrm{P}_{\text {oter }} c / a 4-c b x^{R}$ & (Lovely et al., 2011) \\
\hline 1/2Urho1 & $a 1 b 1 / P_{G a p}-r h o 1-h y g^{R}$ & (Pham et al., 2009) \\
\hline 2/9Urho1 & $a 2 b 2 / P_{G a p}-r h o 1-h y g^{R}$ & (Pham et al., 2009) \\
\hline 1/2pUMEX & $a 1 b 1 / P_{G a p}-h y g^{R}$ & This study \\
\hline 2/9pUMEX & $a 2 b 2 / P_{G a p}-h y g^{R}$ & This study \\
\hline $2 / 11$ & $a 2 b 1$ & (Smith et al., 2004) \\
\hline $2 / 14$ & $a 1 b 2$ & (Smith et al., 2004) \\
\hline $2 / 11 \Delta s m u 1$ & $a 2 b 1 s m u 1 \Delta:: c b x^{R}$ & This study \\
\hline $2 / 14 \Delta s m u 1$ & $a 1 b 2 s m u 1 \Delta:: c b x^{R}$ & This study \\
\hline 2/11smu1Otef & $a 2 b 1 \mathrm{P}_{\text {oter }}-s m u 1-c b x^{R}$ & This study \\
\hline 2/14smu1Otef & $a 1 b 2 \mathrm{P}_{\text {otef }}-\mathrm{Smu} 1-c b x^{R}$ & This study \\
\hline $2 / 11 \Delta c / a 4$ & $a 2 b 1 c l a 4 \Delta:: h y g^{R}$ & This study \\
\hline $2 / 14 \Delta$ cla 4 & $a 1 b 2 c l a 4 \Delta:: h^{\prime} g^{R}$ & This study \\
\hline 2/11cla4Otef & $a 2 b 1 \mathrm{P}_{\text {oter }}-\mathrm{cla} 4-c b x^{R}$ & This study \\
\hline 2/14cla4Otef & $a 1 b 2 \mathrm{P}_{\text {otef }}-\mathrm{cla} 4-c b x^{R}$ & This study \\
\hline 2/11Urho1 & $a 2 b 1 / P_{G a p}-r h o 1-h y g^{R}$ & This study \\
\hline 2/14Urho1 & $a 1 b 2 / P_{G a p}-r h o 1-h y g^{R}$ & This study \\
\hline 2/11pUMEX & $a 2 b 1 / \mathbb{P}_{G a p}-h y g^{R}$ & This study \\
\hline 2/14pUMEX & $a 1 b 2 / P_{G a p}-h y g^{R}$ & This study \\
\hline
\end{tabular}


PCR runs had initial denaturation temperature $94^{\circ} \mathrm{C}$ for $4 \mathrm{~min}$ followed by 40 cycles of denaturation at $94^{\circ} \mathrm{C}$ for $30 \mathrm{sec}$, annealing temperature specific to primer set for $30 \mathrm{sec}$, and extension at $72^{\circ} \mathrm{C}$ for $1 \mathrm{~min} / \mathrm{bp}$. To complete reactions a final extension time for $10 \mathrm{~min}$ at $72^{\circ} \mathrm{C}$ was used.

Table 2: List of primers

\begin{tabular}{ll}
\hline Primer & Sequence $\left(5^{\prime}-3^{\prime}\right)$ \\
\hline Smu1000F & ACGCTCCATACCATCTCGTC \\
Smu1000R & GAACACTTTGAGGCAGCACA \\
mds_ste5in & GCGGCATCGCAACATTGTCAAC \\
mds_ste3in & TCGCGATGGATAACGCCGTGT \\
Smu1f5Xmal & TTCCCGGGCATCGCTTCGAATCCTTCTC \\
Smu1r3Sacl & TTGAGCTCTGGATGTGATTGTTCGTGGT \\
Cbx69R & GATTCGGGACTCGGACAAC \\
Cbx1815L & CAGGACGTGTACCTAGCGATTT \\
CKOLeft & TTCAGTTGTCGTTGCGTGAG \\
CKORight & ACCGTGTGGGTGAGTGG \\
Cla4Up5 & TGTCTGTCTGCCTGCATCTC \\
Hyg90R & CGTGTCGATTCACGTTTTGTAG \\
\hline
\end{tabular}

GENETIC MANIPULATION: The smu1::cbx $x^{R}$ construct was amplified via PCR from genomic DNA of strain 10/18 1 smu1 using primer set Smu1000F and Smu1000R and the cla4 $4:$ hyg $g^{R}$ construct was amplified by PCR from the FB2 $\triangle$ cla4 strain using primer set CKOLeft and CKORight. PCR products were separated on $0.8 \%$ agarose gels using gel electrophoresis and were purified using GeneClean III Kit (MP Biomedicals, Solon, $\mathrm{OH}$ ). U. maydis protoplasts were transformed using the purified constructs. The protocol for U. maydis protoplast preparation and transformation was as described previously (Brachmann et al., 2004). Two independent transformants were tested for both $\Delta s m u 1$ and $\triangle c l a 4$ mutation. Transformants were confirmed by PCR amplification and DNA sequencing using Big Dye Terminator v 3.1 Cycle sequencing Kit (Applied Biosystems). 
MATING ASSAY AND PLANT INFECTION: Exponentially growing $U$. maydis cells having a concentration of $10^{7}$ cells $\mathrm{ml}^{-1}$ were used for plate mating assay (Mayorga and Gold, 1999) and plant infection (Gold et al., 1997). Liquid YEPS medium was inoculated using overnight culture so as to have an optical density $\left(A_{600}\right)$ of 0.1 and cells were grown till exponential growth phase before harvesting. For charcoal plate mating assay, a $20 \mu \mathrm{l}$ volume was spotted for each mating mixture and observed till $48 \mathrm{hrs}$ post inoculation. Mating efficiency was measured in terms of intensity of 'White Fuzz' for each spot. Average intensity of each spot was measured using MetaMorph imaging software (MDS Analytical Technologies Inc., Mississauga, Ontario, Canada). For plant infection, Sweet Corn seeds, Burpee's Golden Bantam (Warminster, PA) were used and plants were grown and maintained in a growth chamber (Conviron, model E15) between a temperature range $20-29^{\circ} \mathrm{C}$ and relative humidity between $65-75 \%$. Light was provided by a combination of fluorescence and incandesce. A $100 \mu$ l volume of each mating mixture was injected through stem of 8 days old seedling and for each mating mixture at least 30 plants were used. Plants were observed for 21 days after inoculation (DAI) and disease index was rated on a scale of $0-5$ as described previously (Lovely et al., 2011). Images were taken using Canon camera (10.0 Mega pixels) having ISO set at 80 and processed using Adobe Photoshop 3.0.

COLONY MORPHOLOGY: To observe filamentation under nitrogen limiting environment, single colony streaks were prepared for the strains on solid SLAD (low nitrogen) medium and grown at $25^{\circ} \mathrm{C}$ for 4 days after inoculation 
(DAI). Single colony images were taken using Nikon Eclipse TE 200 microscope (Nikon Inc., Melvin, NY), Nikon DS-Fi1 camera using NIS-Elements F 3.2 software and processed using Adobe Photoshop 3.0. Extent of filamentation was measured by overlaying a grid over images at same magnification and number of squares covering central region of each colony and filaments were counted. A ratio of number of squares covering filamentous region and central region was calculated for at least three colonies for each strain.

\section{CELL MORPHOLOGY, STAINING AND MICROSCOPY: Exponentially} growing $\Delta c l a 4$ mutants and WT $U$. maydis cells were harvested to wash off media before staining with calcoflour white (CFW) at a final concentration of 0.1 $\mu \mathrm{g} / \mathrm{ml}$ (CFW, Fluorescent Brightener 28; Sigma, St. Louis, MO). After $10 \mathrm{~min}$ of staining cells were washed with and re-suspended in distilled water. To visualize cells, a UV filter was used and images were taken using Nikon Eclipse TE 200 microscope (Nikon Inc., Melvin, NY) and NIS elements software and processed using Adobe Photoshop 3.0.

STATISTICAL ANALYSIS: SAS version 9.3 was used for all statistical procedures. To analyze charcoal plate mating assay and disease indices data a mixed model was used to estimate contrasts between mean values of intensities or disease indices respectively among all compatible mating pairs. The $\mathrm{p}$-values were assigned significance based upon the following cut off values: * $p \leq 0.05$, ${ }^{* *} p \leq 0.005,{ }^{* * *} p \leq 0.0005$. To analyze colony morphology data for filamentation, ratios of squares as described earlier were used to conduct Dunnett's t Test and were compared to their respective parental WT as a control. 


\section{RESULTS}

To address whether the particular a locus or the allele type at the $b$ locus is involved in regulating behavior in $U$. maydis, the strains with genetic background $a 1 b 2$ and $a 2 b 1$ were selected for this study. Deletion and/or overexpression strains were constructed for each gene of interest in these genetic backgrounds for the purpose of comparison with the $a 1 b 1$ and $a 2 b 2$ genetic backgrounds used in previous published studies (Smith et al., 2004), (Leveleki et al., 2004), and (Lovely et al., 2011).

\section{MATING EFFICIENCY AND PATHOGENICITY IN U. MAYDIS MUTANTS:}

The smu1 mutants: $U$. maydis smu1, a p-21 activated kinase (PAK) has an effect on mating as it controls expression of mating pheromone (Mfa). As observed on YPD medium with the activated charcoal plate mating assay, mating efficiency was reduced compared to WT in smu1 disruption strains, even when only one of the mating partners had the smu1 disruption. This reduction was more pronounced when the disruption was in a $2 b 2$ background as compared to when it was found in $a 1 b 1$ background. When one of the mating partners overexpressed smu1, mating efficiency was slightly increased as compared to WT mating pair when smu1 was over-expressed in an a1b1 background (Smith et al., 2004). To test mating efficiency for $\Delta$ smu1 mutants in $a 1 b 2$ and $a 2 b 1$ genetic background, $U$. maydis cells were spotted on to YPD medium with activated charcoal (Figure 6 ). The reduction in mating efficiency in a1b2 $\Delta s m u 1$ with a2b1WT was statistically significant as compared to WT mated 


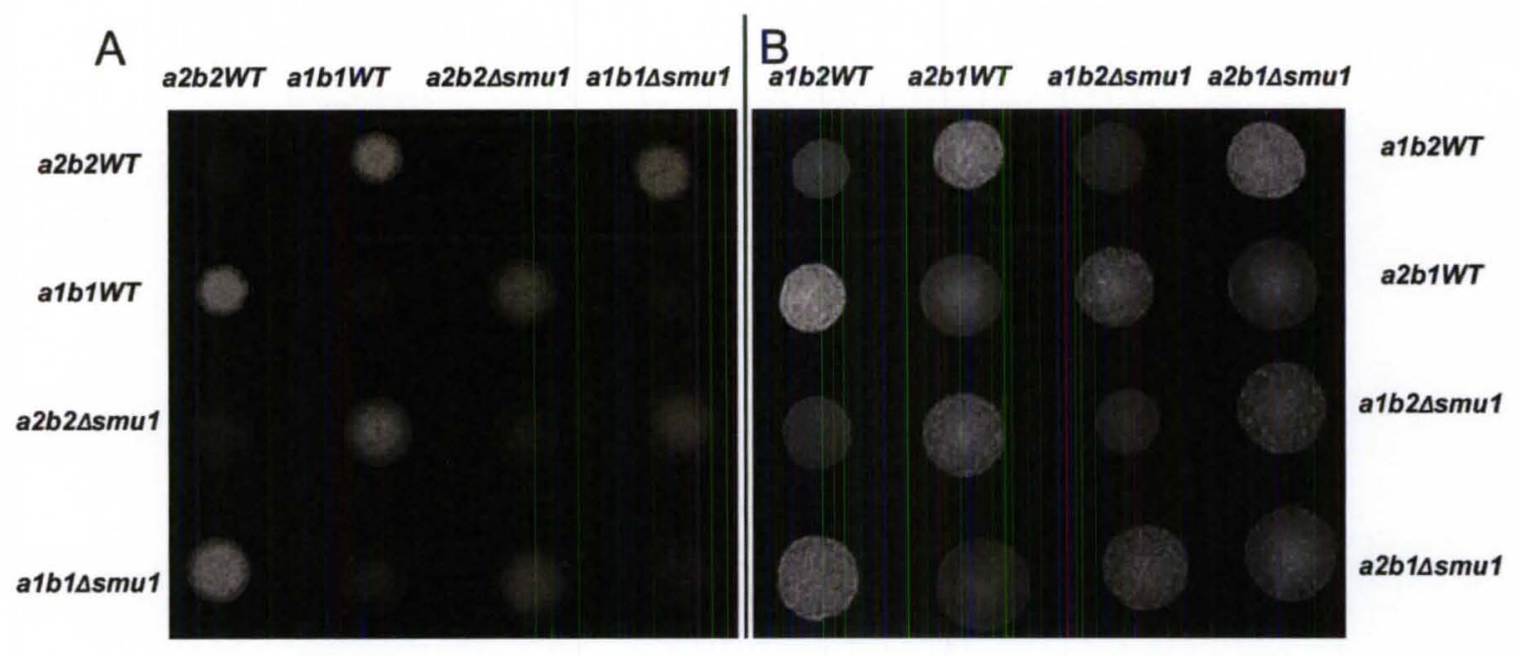

Figure 6: Comparison of mating efficiency of $\Delta s m u 1$ mutants on YPD media with activated charcoal $36 \mathrm{hrs}$ after inoculation. Genetic background a1b1-a2b2 (A), Genetic background $a 1 b 2-a 2 b 1$ (B). Intensity of fuzz as a measure of mating efficiency due to production of hyphae was quantified as described in Materials and Methods.

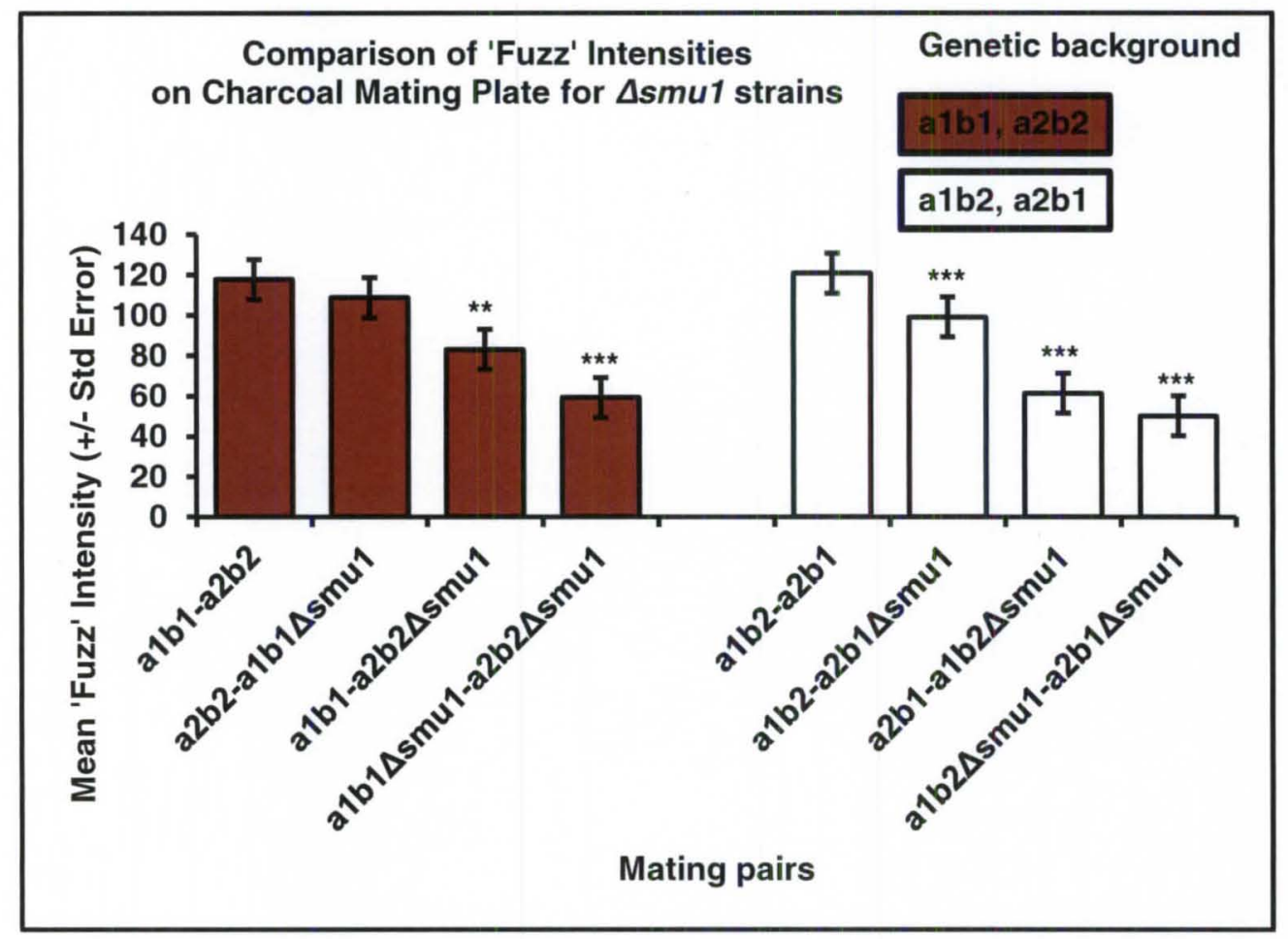

Figure 7: Statistical analysis of mating efficiency of $\Delta s m u 1$ mutants on YPD media with activated charcoal $36 \mathrm{hrs}$ after inoculation. The $\mathrm{p}$-values were derived with contrasts between mean values of intensities between each mating pair and WT mating pair as control. ${ }^{\star} p \leq 0.05,{ }^{\star *} p \leq 0.005,{ }^{* \star *} p \leq 0.0005$ 
pair (Figure 7). Earlier studies had also revealed that the smu1 disruption

mutants exhibited reduction in disease indices for plant infection as well, with

more reduction in disease index when the injected mating pair had smu1

disruption in a2b2 background (Smith et al., 2004).To examine the degree of

plant pathogenicity in $a 1 b 2$ and $a 2 b 1$ genetic background for $\Delta s m u 1$ deletion

mutants, 8-day old corn plants were injected with premixed compatible mating

pairs and pathogenicity was measured in terms of disease index as described in

Materials and Methods.

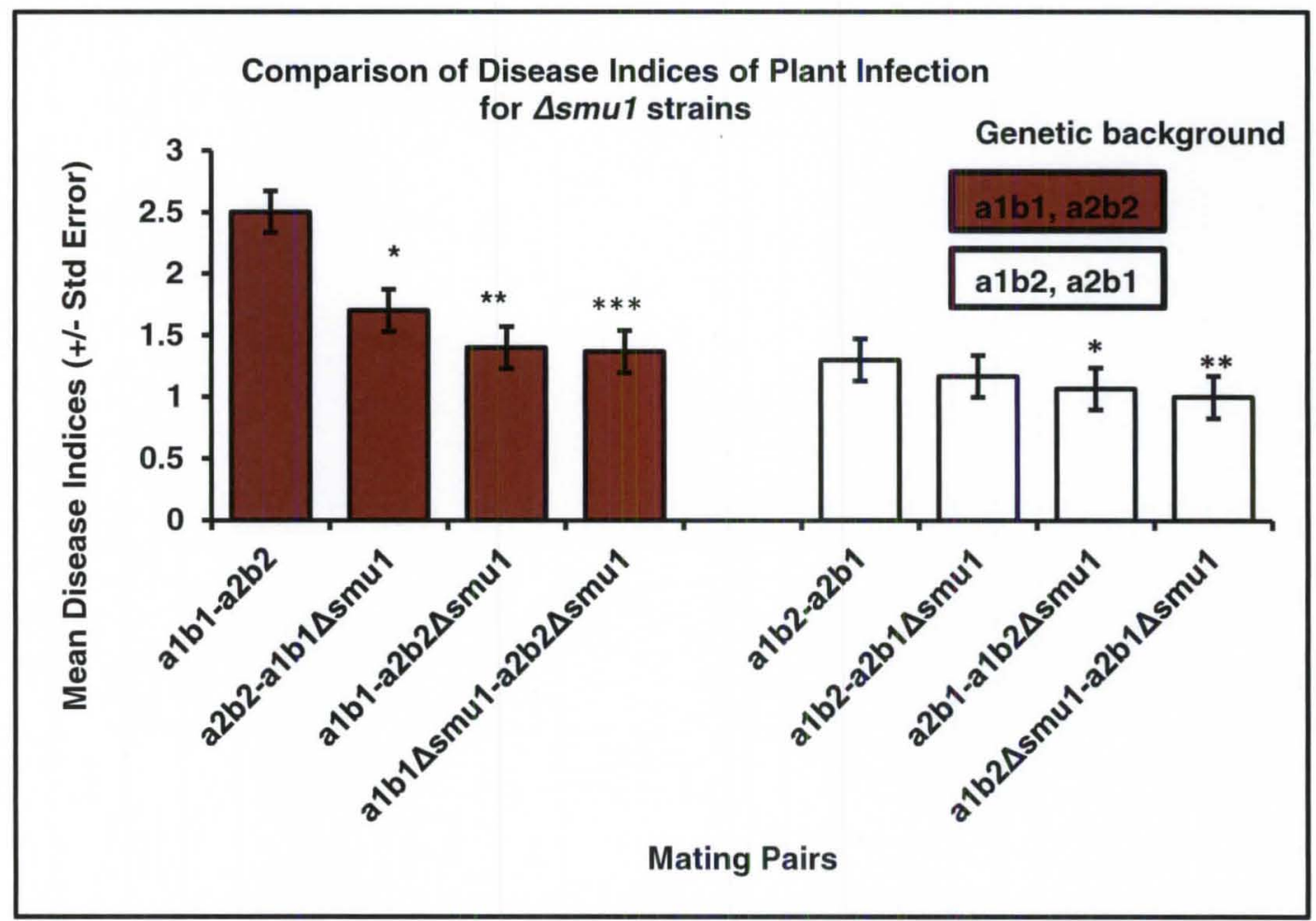

Figure 8: Comparison of disease indices for plant infection at 21 days after inoculation. 8 day old plants were injected with $100 \mu$ l of inocula of mating pairs growing logarithmically and having concentration $10^{7}$ cells $\mathrm{ml}^{-1}$. The disease index was measured in terms of disease symptoms that are assigned a numerical value ranging from $0-5.0=$ no infectious symptom, $1=$ chlorosis, $2=$ small leaf tumors, 3 = large leaf or small stem tumors, $4=$ large stem tumors, and $5=$ plant death. The $p$-values were derived with contrasts between mean values of the disease index between each mating pair and WT mating pair as control. ${ }^{*} p \leq 0.05,{ }^{* *} p \leq 0.005,{ }^{* * *} p \leq 0.0005$ 


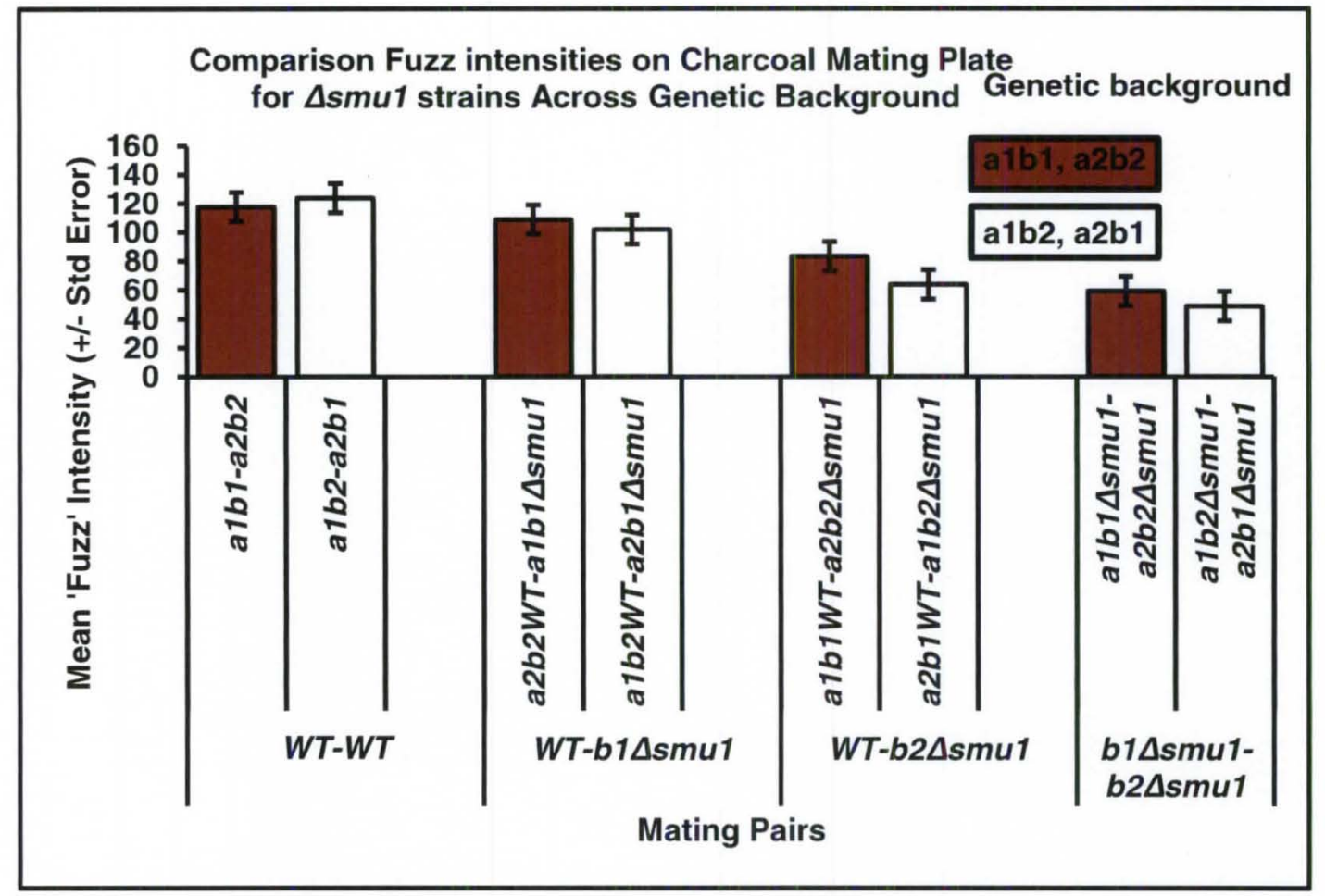

Figure 9: Comparison of mating efficiency across genetic background for $\Delta s m u 1$ mutants as observed on YPD medium with activated charcoal $36 \mathrm{hrs}$ after inoculation. The p-values were derived with contrasts between mean values of the intensities of fuzz between genetic background paired in each comparison $p \leq 0.05,{ }^{* *} p \leq 0.005,{ }^{* \star *} p \leq 0.0005$

Also, as a control for plant pathogenicity experiment, corn plants were injected with pre-mixed compatible mating partners for smu1 disruption in $a 1 b 1$ and a2b2 genetic background. Statistical analysis of data for disease indices for a1b1 and a2b2 background once again revealed that when smu1 was disrupted in a2b2 background the disease index was less as compared to that of WT then when the disruption was present in a1b1 background. When statistical analysis was done using disease indices data for smu1 disruption in $a 1 b 2$ and $a 2 b 1$ genetic background there was a significant reduction in disease index when a2b1WT was mated with $a 1 b 2$ strain that had the smu1 disruption as compared to WT mating pair and a pair having deletion in the a2b1 background mated with a1b2WT (Figure 13). We also wanted to examine overall change for mating 
efficiency and disease indices across the genetic backgrounds a1b1, a2b2 and $a 1 b 2, a 2 b 1$ for $\Delta s m u 1$ mutants. When data from plate mating assays was analyzed for overall change for $\Delta s m u 1$ mutants we found that a1b1WT mated with a2b2WT with almost equal efficiency as a1b2WT mated with a2b1WT and mutants in both the genetic backgrounds also mated with equal efficiency. The statistical analysis did not show any significant difference in the mating efficiency across genetic background (Figure 14). However, there was a significant difference in disease indices between both the genetic backgrounds for WT-WT pair and when smu1 was disrupted in a background having b1 allele. For example, when a1b1WT mated with a2b2WT was

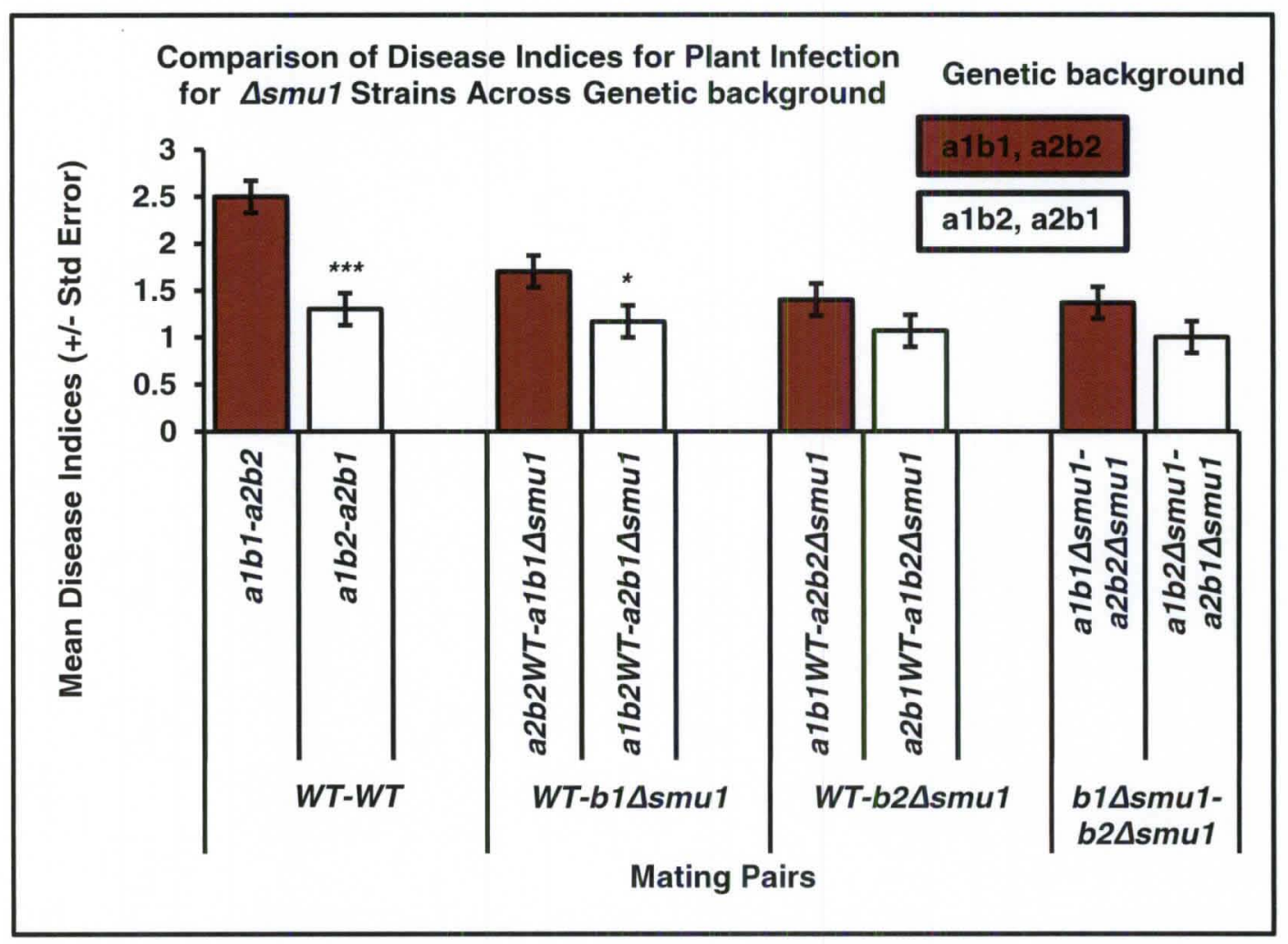

Figure 10: Comparison of disease indices across genetic background for $\Delta s m u 1$ mutants. The $p$ values were derived with contrasts between mean values of the disease indices between genetic background paired in each comparison of disease index. ${ }^{*} p \leq 0.05,{ }^{* *} p \leq 0.005,{ }^{* \star *} p \leq 0.0005$ 
compared with $a 1 b 2 \mathrm{WT}$ mated with $a 2 b 1 \mathrm{WT}$ for disease index, then there was a significant lower disease index for latter infections. Similarly, the mating pair where the smu1 deletion was in the a2b1 background showed a significant decrease relative to when the deletion was in the a1b1 background. In contrast, $a 1 b 1 \mathrm{WT}$ mated with $a 2 b 2 \Delta s m u 1$ had a disease index similar to $a 2 b 1 \mathrm{WT}$ mated with $a 1 b 2 \Delta s m u 1$ and when both the mating partners were defective for smu1 in either genetic background then disease index was the same across genetic background (Figure 15).

Since the above results suggested the both mating and pathogenicity phenotypes seen with smu1 deletion appeared to follow the $b$ allele present in a particular genetic background. Background dependent phenotypes for overexpression of smu1 (Smith et al., 2004) and rho1 (small GTPase) (Pham et al., 2009) as well as for cla4 (a PAK like kinase) deletion (Leveleki et al., 2004) could also be linked to a particular mating locus allele and thus were also tested. For that purpose I conducted mating assays for these mutations in $a 1 b 2, a 2 b 1$ genetic backgrounds and compared results to those from $a 1 b 1, a 2 b 2$ genetic backgrounds.

For strains over-expressing the smu1 gene, a slight but not statistically significant increase in mating efficiency was reported earlier when smu1 overexpressing $a 1 b 1$ was allowed to mate with $a 2 b 2 \mathrm{WT}$ as compared to $a 1 b 1 \mathrm{WT}$ mated with a2b2WT (Smith et al., 2004). Also, the mating efficiency for strains over-expressing smu1 was not statistically different from WT in $a 1 b 2$ and $a 2 b 1$ 


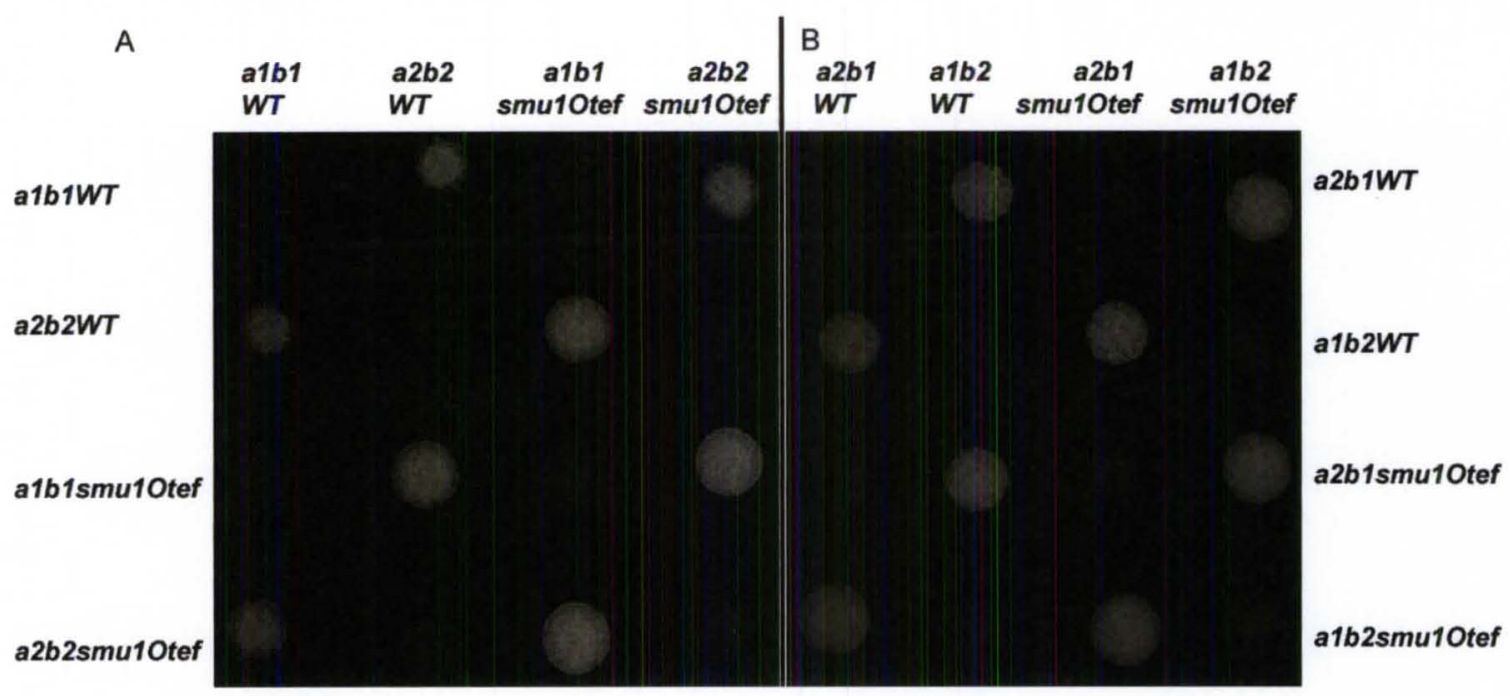

Figure 11: Comparison of mating efficiency of smu1 over-expression mutants on YPD medium with activated charcoal $36 \mathrm{hrs}$ after inoculation. Genetic background $a 1 \mathrm{~b} 1$ $a 2 b 2$ (A) and genetic background $a 1 b 2-a 2 b 1$ (B). Intensity of fuzz as a measure of mating efficiency due to production of hyphae was quantified as described in Materials and Methods.

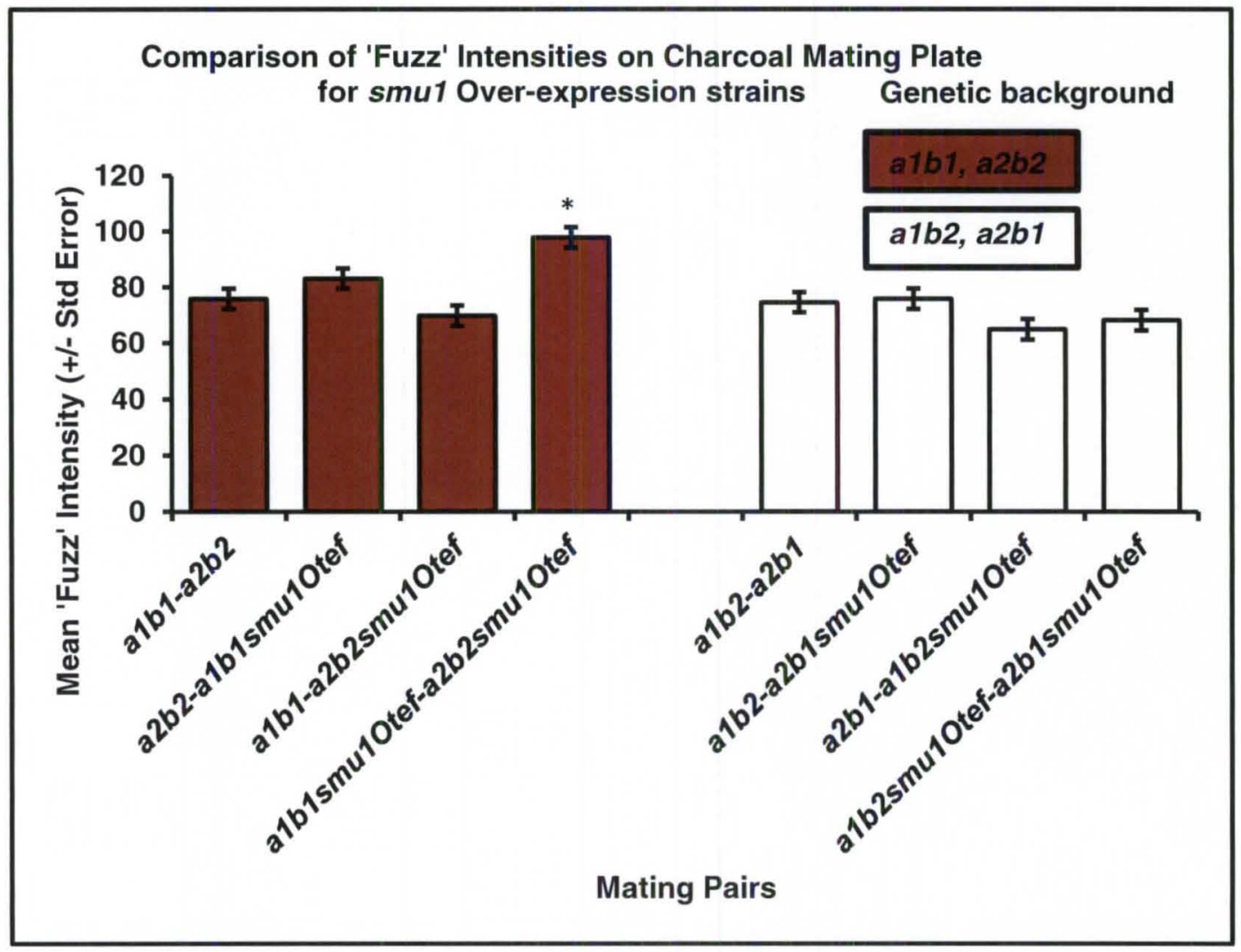

Figure 12: Statistical analysis of mating efficiency of smu1 over-expression mutants on YPD media with activated charcoal $36 \mathrm{hrs}$ after inoculation. Genetic background $a 1 \mathrm{~b} 1$ a2b2 (left side of graph), Genetic background a1b2-a2b1 (right side of graph). The pvalues were derived with contrasts between mean values of intensities between each mating pair and WT mating pair as control. ${ }^{*} p \leq 0.05,{ }^{* *} p \leq 0.005,{ }^{* \star *} p \leq 0.0005$ 
genetic backgrounds when either one of the compatible mating partners or both the partners had over-expressed smu1 (Figure 16 and 17).

The cla4 mutants: A PAK-like kinase, Cla4, is important for cell polarity, proper budding and filamentation. Unlike $\Delta s m u 1$ mutants, the $\Delta c l a 4$ mutants showed reduction in mating efficiency when $a 2 b 2 \mathrm{WT}$ was mated with a partner that had $\Delta c l a 4$ mutation in a1b1 genetic background. For $\Delta c / a 4$ strains mating efficiency was observed on PDA medium with activated charcoal. Also, a1b1 $\Delta \mathrm{cla} 4$ mutant mated with a2b2WT was less pathogenic to corn plant as compared to WT mated pair (Leveleki et al., 2004). The genetic background dependent mating behavior disappeared in the case of the $\Delta c / a 4$ mutation in a1b2, a2b1 genetic backgrounds (Figure 18) which was also supported by statistical analysis of fuzz intensity data (Figure 19). The rho1 over-expression mutants: In U. maydis, Rho1, a small GTPase, is required for survival and appears to play a role upstream in regulation of $b$ locus and interacts with Smu1. Similar to smu1 mutants, as observed on YPD medium with activated charcoal, over-expression of $r h o 1$ in an a2b2 genetic background mated with $a 1 b 1 \mathrm{WT}$ exhibited reduction in mating as compared to WT mated pair and a2b2WT mated with a $1 b 1$ overexpressing rho1. Also, the mating efficiency was reduced when both the partners had over-expression of rho1 (Pham et al., 2009). These observations were supported by statistical analysis as well. But when rho1 over-expression was tested in the $a 1 b 2$ and $a 2 b 1$ genetic backgrounds then the mating locus dependent behavior for mating disappeared. All the mutants mated as efficiently as the $a 1 b 2 \mathrm{WT}$ and $a 2 b 1 \mathrm{WT}$ mating pair (Figure 20 and Figure 21). 


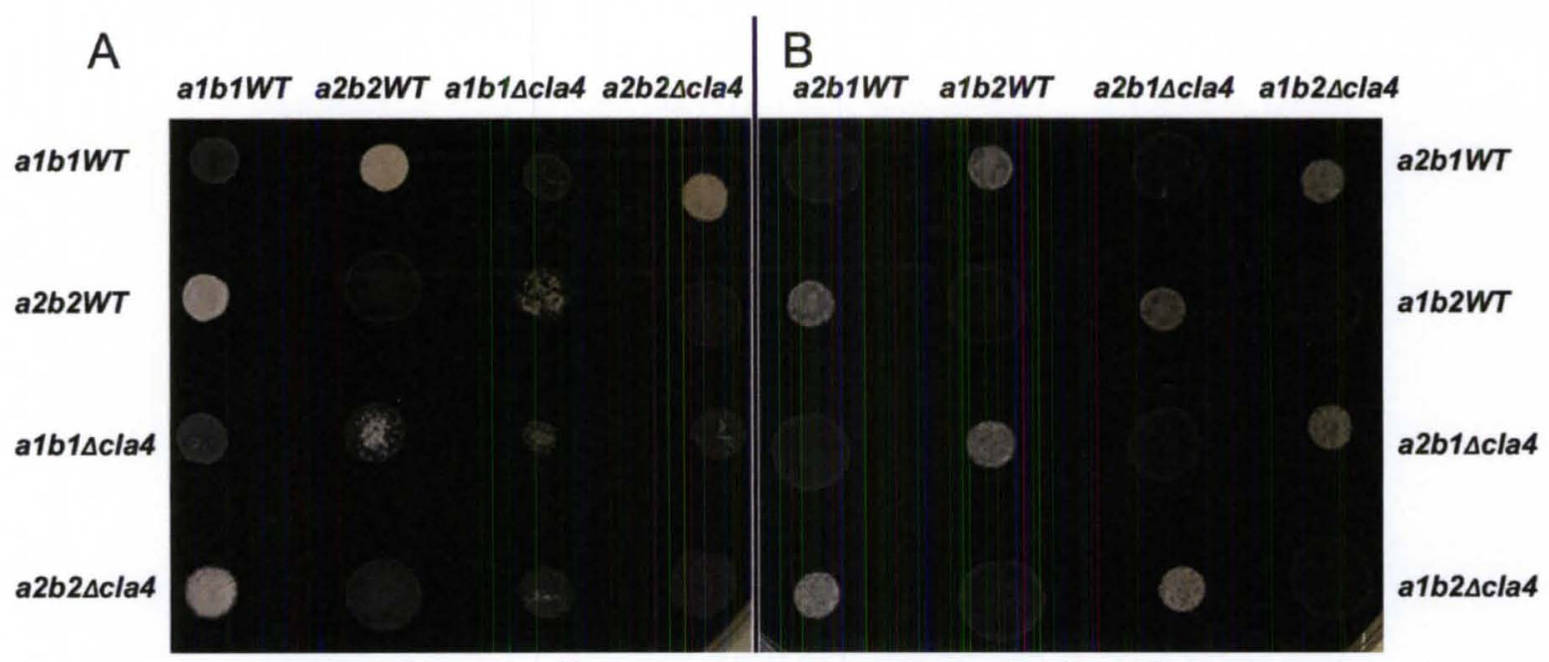

Figure 13: Comparison of mating efficiency of $\triangle$ cla4 mutants on PDA medium with activated charcoal 36 hrs after inoculation. Genetic background a1b1-a2b2 (A) and genetic background a1b2-a2b1 (B). Intensity of fuzz as a measure of mating efficiency due to production of hyphae was quantified as described in Materials and Methods.

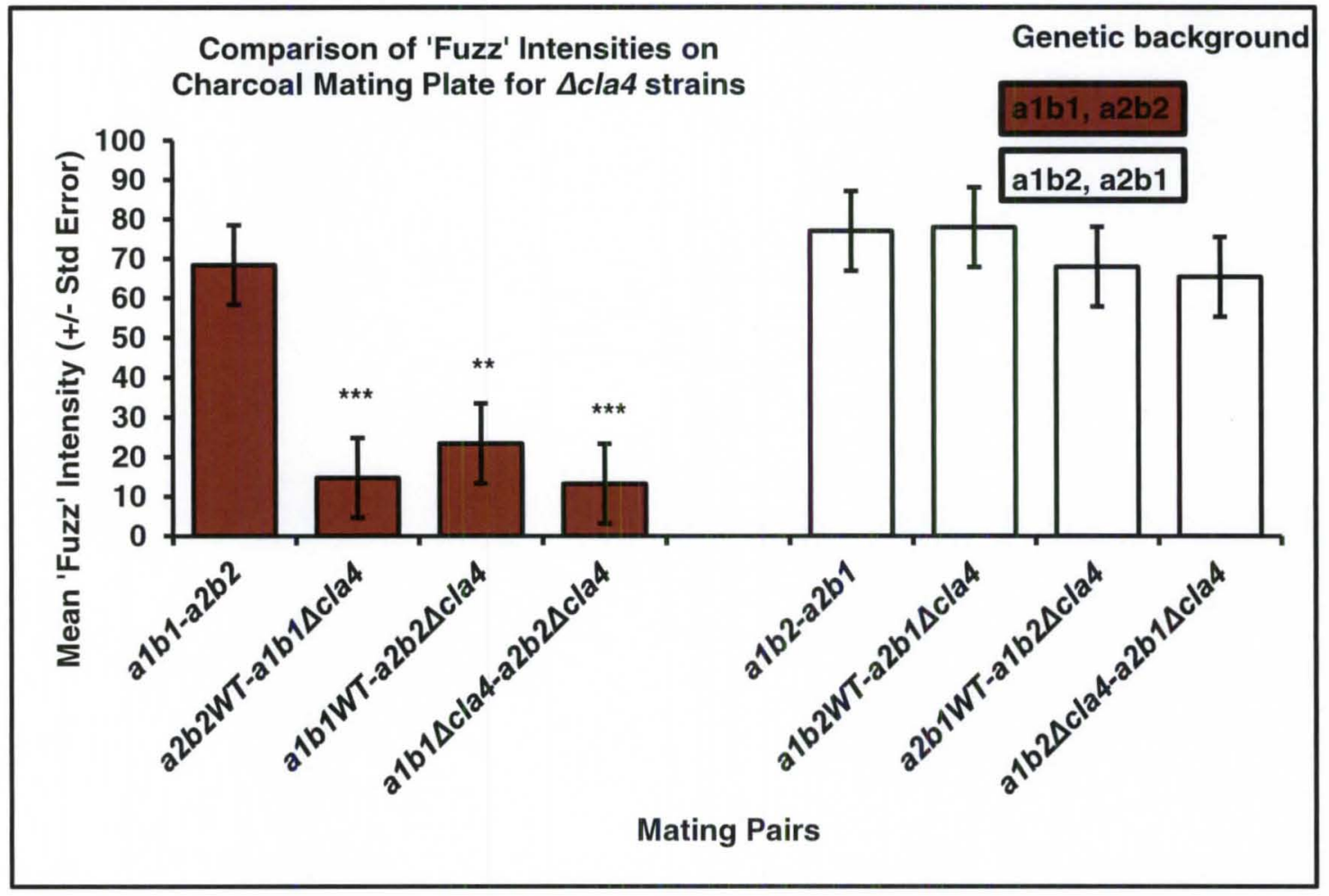

Figure 14: Statistical analysis of mating efficiency of $\triangle c l a 4$ mutants on PDA media with activated charcoal $36 \mathrm{hrs}$ after inoculation. Genetic background $a 1 b 1$-a2b2 (left side of graph), Genetic background $a 1 b 2-a 2 b 1$ (right side of graph). The p-values were derived with contrasts between mean values of intensities between each mating pair and WT mating pair as control. ${ }^{*} \mathrm{D} \leq 0.05$. ${ }^{* *} \mathrm{D} \leq 0.005$. ${ }^{* * *} \mathrm{D} \leq 0.0005$ 


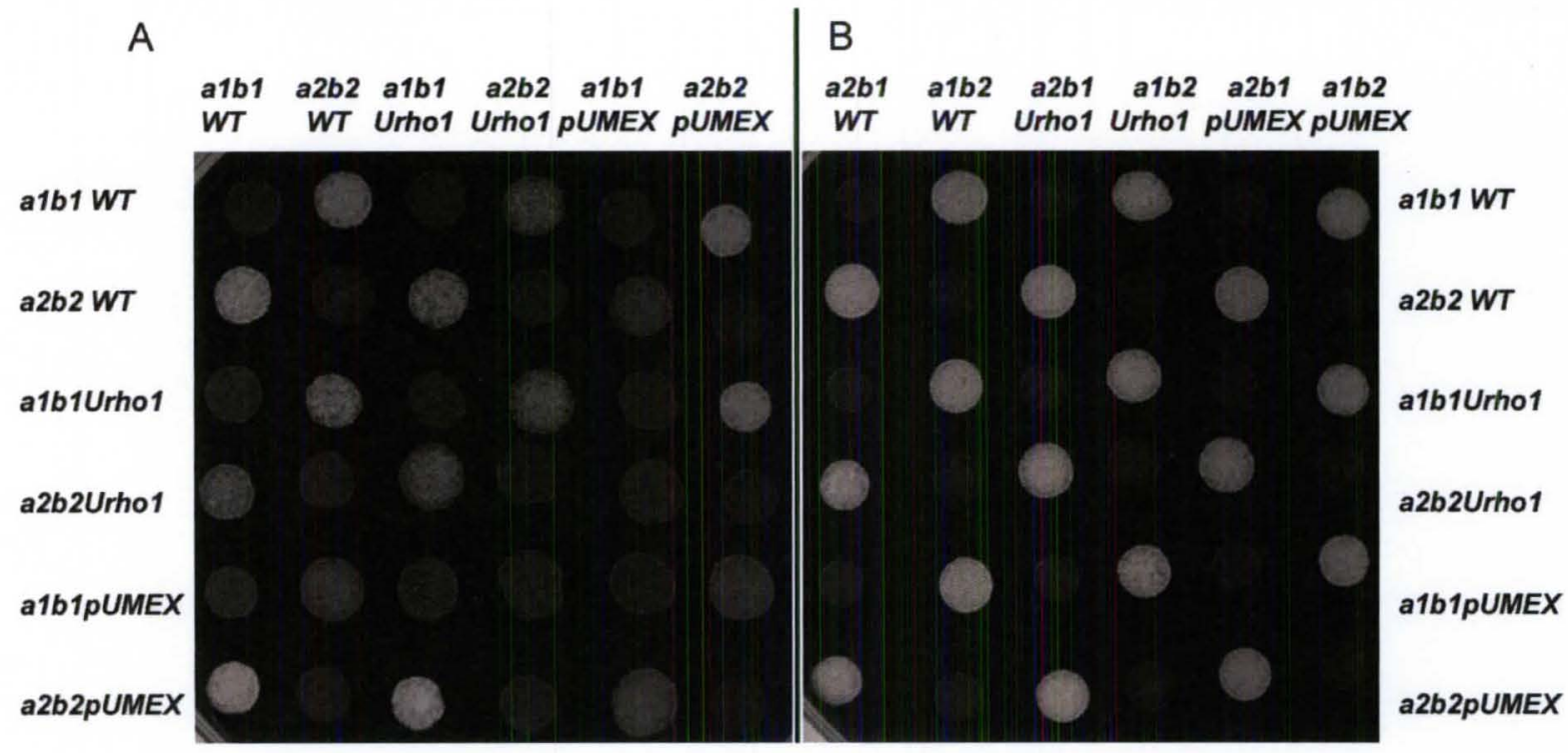

Figure 15: Comparison of mating efficiency of rho1 over-expression mutants on YPD medium with activated charcoal $36 \mathrm{hrs}$ after inoculation. Genetic background a1b1-a2b2 (A) and genetic background $a 1 b 2-a 2 b 1(B)$. Intensity of fuzz as a measure of mating efficiency due to production of hyphae was quantified as described in Materials and Methods. Strains with pUMEX plasmid were tested as vector only controls to eliminate as background any difference due solely to presence of the plasmid.

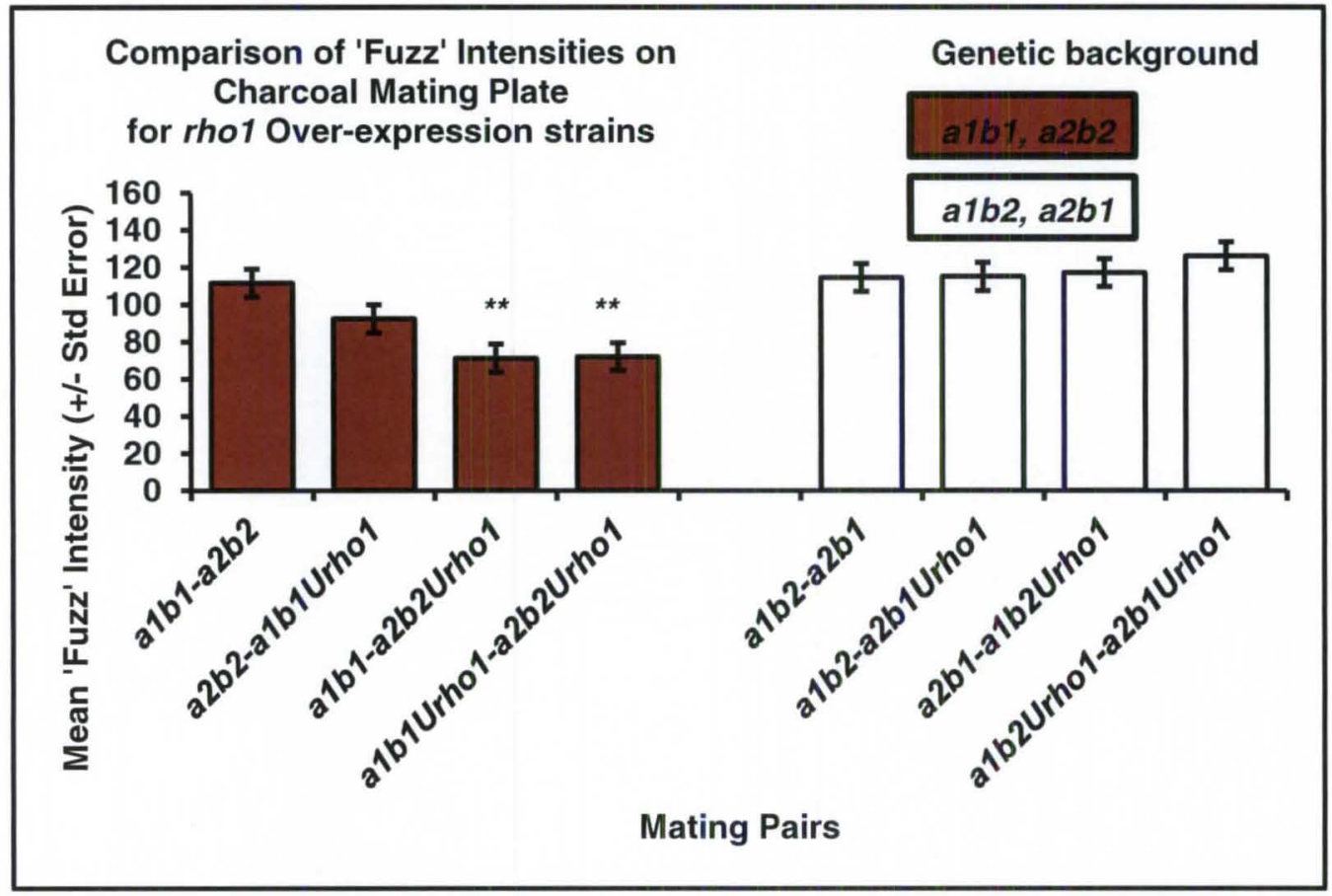

Figure 16: Statistical analysis of mating efficiency of rho1 over-expression mutants on YPD medium with activated charcoal $36 \mathrm{hrs}$ after inoculation. Genetic background $a 1 b 1-a 2 b 2$ (left side of graph) and genetic background $a 1 b 2-a 2 b 1$ (right side of graph). Intensity of fuzz as a measure of mating efficiency due to production of hyphae was quantified as described in Materials and Methods. The $p$-values were derived with contrasts between mean values of intensities between each matinq pair and WT mating pair as control. ${ }^{*} \mathrm{p} \leq 0.05,{ }^{* *} \mathrm{p} \leq 0.005$. 
COLONY MORPHOLOGY IN U. MAYDIS MUTANTS: In addition to mating behavior as observed and discussed above for alteration in genes, $U$. maydis behaves differently under low ammonium conditions depending upon the type of mutation present in the genetic background (Smith et al., 2004) (Lovely et al., 2011). U. maydis produces smooth colonies on rich media, i.e., when abundant fermentable carbon and nitrogen is available. Under low nitrogen conditions like SLAD media, colonies become filamentous.

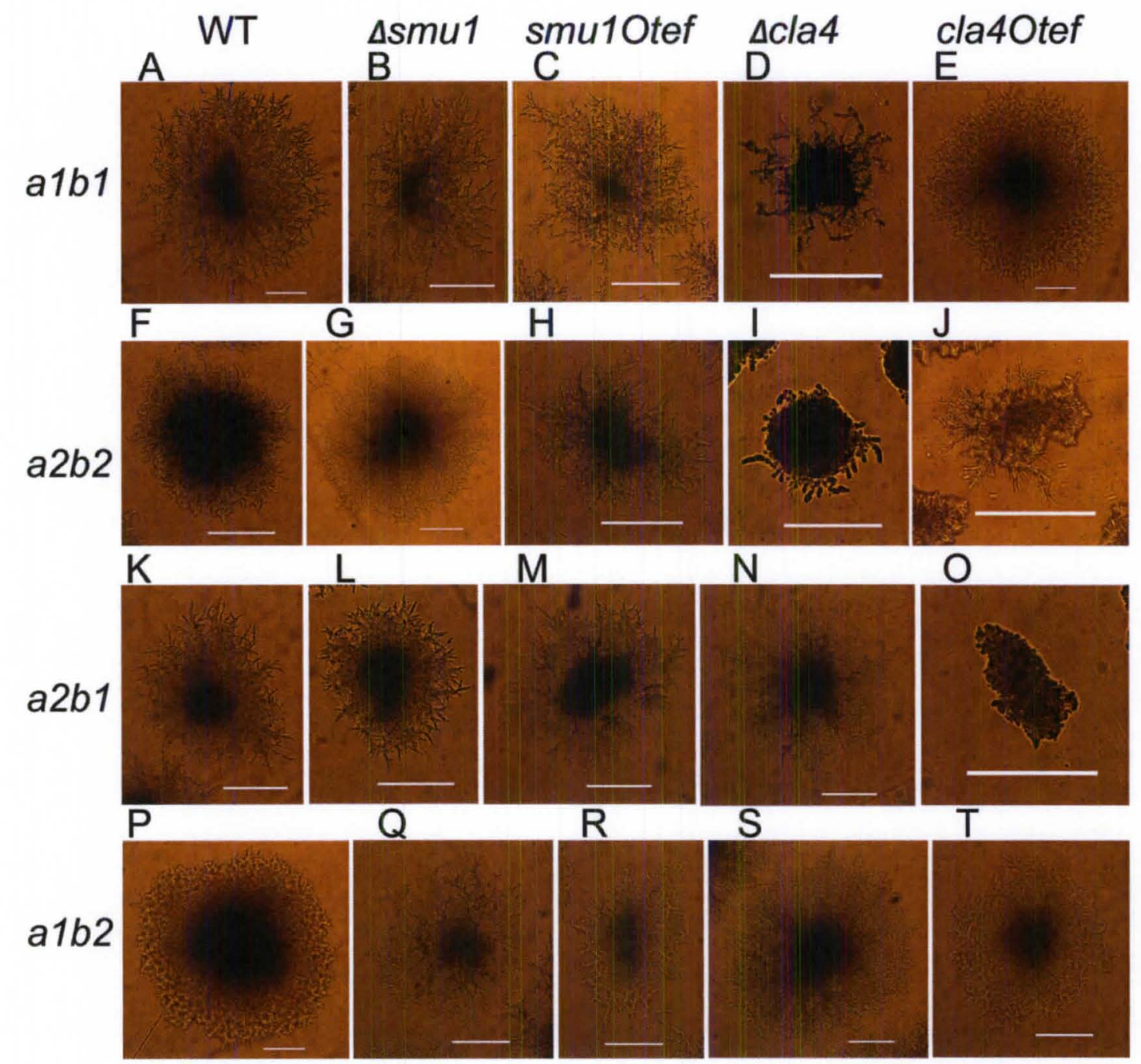

Figure 17: Colony morphology under low ammonium condition 4 days after inoculation on SLAD medium. The filamentation behavior was altered and was dependent upon the type of mutation and genetic background. The scale bar corresponds to $200 \mu \mathrm{m}$. 
Statistical analysis showed that the a1b1WT was more filamentous as compared to $a 2 b 2 \mathrm{WT}$. To examine filamentous behavior for deletion and over-expression smu1 and cla4 in the $a 1 b 2$ and $a 2 b 1$ genetic backgrounds the mutants were streaked onto SLAD medium and extent of filamentation was quantified as described in Materials and Methods. Also, the mutants in $a 1 b 1$ and $a 2 b 2$ backgrounds were streaked onto SLAD for direct comparison. Once again the behavior was observed to be genetic background dependent except for smu1 disrupted strains. It was reported earlier that if $s m u 1$ was disrupted in the $a 2 b 2$ genetic background then it becomes less filamentous as compared to a2b2WT (Smith et al., 2004). But statistical analysis using a more quantitative approach in the current study revealed that the a2b2 $\Delta s m u 1$ was significantly more filamentous as compared to $a 2 b 2 \mathrm{WT}$. Moreover, the smu1 disruption in the $a 1 b 2$ genetic background was more filamentous as compared to a1b2WT. Strains over-expressing smu1 were significantly more filamentous in the $a 1 b 1$ and $a 2 b 1$ genetic background when compared to their respective parental WT (Figure 22). Statistical data for smu1 disrupted and over-expression strains is given in Table 3.

In the case of $\Delta$ cla 4 mutants, there was a significant reduction in filamentation in the $a 1 b 1$ and $a 2 b 2$ genetic backgrounds when compared to their respective parental WT, whereas, filamentation behavior was not affected by cla 4 deletion in $a 1 b 2$ and $a 2 b 1$ genetic backgrounds. For strains with cla4 overexpression, a1b1 was significantly more filamentous when compared to $a 1 b 1 \mathrm{WT}$, while over-expression in the $a 2 b 2$ was less filamentous, but the reduction was 
Table 3: Dunnett's $t$ Test for Filamentation for smu1 mutants compared to their respective parental WT as a control

\begin{tabular}{|c|c|c|}
\hline Mutant comparison & Difference between Mean & Phenotype \\
\hline$a 1 b 1 \Delta s m u 1-a 1 b 1 \mathrm{WT}$ & 1.833 & Increase ${ }^{\text {NS }}$ \\
\hline a1b1smu1Otef-a1b1WT & 3.500 & Increase $e^{\star \star \star}$ \\
\hline$a 2 b 2 \Delta s m u 1-a 2 b 2 \mathrm{WT}$ & 2.900 & Increase $e^{\star \star \star}$ \\
\hline$a 2 b 2$ smu1Otef-a2b2WT & 0.266 & Increase NS \\
\hline$a 1 b 2 \Delta s m 1-a 1 b 2 \mathrm{WT}$ & 3.300 & Increase $e^{\star \star \star}$ \\
\hline a1b2smu1Otef-a1b2WT & 0.166 & Increase ${ }^{\text {NS }}$ \\
\hline$a 2 b 1 \Delta s m u 1-a 2 b 1 \mathrm{WT}$ & -2.100 & Decrease ${ }^{\star \star *}$ \\
\hline$a 2 b 1 s m u 1 O t e f-a 2 b 1 \mathrm{WT}$ & 3.300 & Increase $e^{\star \star \star}$ \\
\hline \multicolumn{3}{|c|}{ Comparisons significant at the 0.05 level are indicated by ${ }^{* \star *} ;$ NS, not significant } \\
\hline \multicolumn{3}{|c|}{$\begin{array}{l}\text { Table 4: Dunnett's t Test for Filamentation for cla4 mutants compared to their } \\
\text { respective parental WT as a control }\end{array}$} \\
\hline Mutant comparison & Difference between Mean & Phenotype \\
\hline$a 1 b 1 \Delta c l a 4-a 1 b 1 \mathrm{WT}$ & -4.500 & Decrease $^{\star * \star}$ \\
\hline a1b1cla4Otef-a1b1WT & 4.767 & Increase $\mathrm{e}^{\star \star *}$ \\
\hline$a 2 b 2 \Delta c / a 4-a 2 b 2 \mathrm{WT}$ & -1.740 & Decrease ${ }^{* \star *}$ \\
\hline$a 2 b 2 c l a 4 O t e f-a 2 b 2 \mathrm{WT}$ & -1.233 & Decrease $^{\text {NS }}$ \\
\hline$a 1 b 2 \Delta c l a 4-a 1 b 2 \mathrm{WT}$ & 0.600 & Increase NS \\
\hline a1b2cla4Otef-a1b2WT & -2.416 & Decrease $^{\mathrm{NS}}$ \\
\hline$a 2 b 1 \Delta c l a 4-a 2 b 1 \mathrm{WT}$ & -0.300 & Decrease $^{\text {NS }}$ \\
\hline a2b1cla4Otef-a2b1WT & -3.803 & Decrease $^{\star \star *}$ \\
\hline
\end{tabular}


not significant as compared to $a 2 b 2 \mathrm{WT}$. Interestingly, reduction was significant in the a2b1cla4Otef as compared to a2b1WT, but was not significant when cla4 was over-expressed in a1b2 as compared to a1b2WT.

CELL MORPHOLOGY IN $\triangle C L A 4$ MUTANTS IN U. MAYDIS: The PAK-like kinase, Cla4, is involved in proper budding and helps the cell in depositing cell wall building material at the growing polar region in normal haploid cigar shaped WT cells. If cla4 was deleted cells divided by fission in the central region in the a2b2 genetic background, whereas deletion of cla4 in a1b1 resulted in branched and septate hyphae (Leveleki et al., 2004). To examine the morphology, cells in the current study were stained with calcoflour white, which stains $1,3-\beta$-glucans present in fungal cell walls.

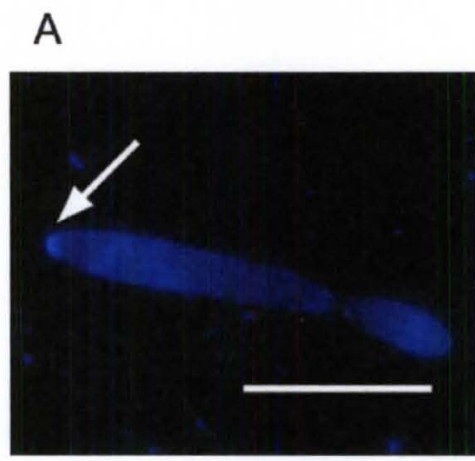

B

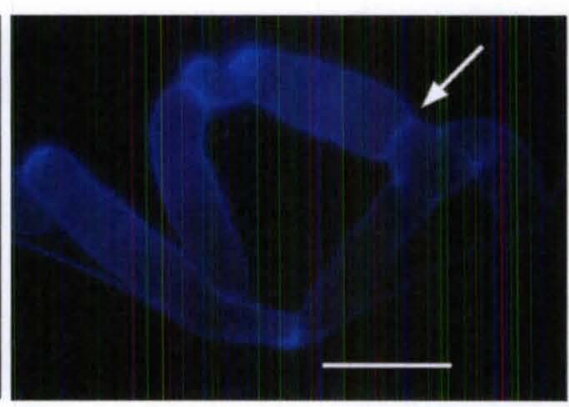

$\mathrm{E}$

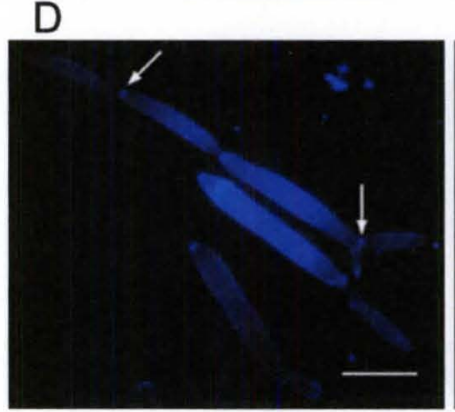

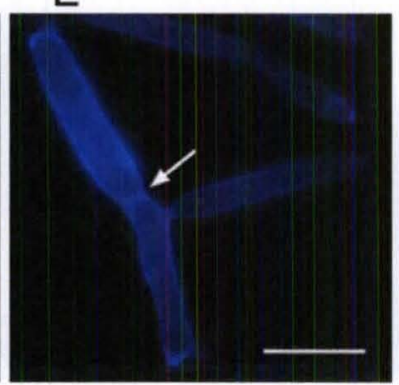

C

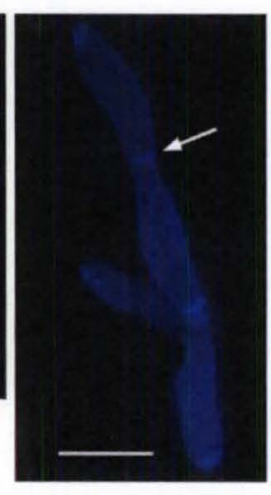

$\mathrm{F}$

Figure 18: Cell morphology of $\triangle$ cla4 mutants. Cells were stained with calcoflour white. WT (A),

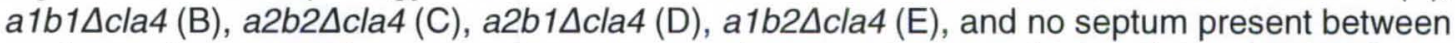
mother and apparent daughter cell, a common phenotype between both $a 2 b 1$ and $a 1 b 2$ cla4 deletion mutants $(F)$. Arrows indicate cross wall septa. Scale bar corresponds to $10 \mu \mathrm{m}$. 
The calcoflour white staining in the $a 1 b 2$ and $a 2 b 1$ genetic backgrounds for $\Delta c l a 4$ mutants showed that cells were defective in depositing cell wall building material at polar region and septal cross walls were present in an irregular pattern in the elongated cells as compared to WT. Sometimes the septum was not present at the expected place such as between mother and apparent daughter cells (Figure 23).

\section{DISCUSSION}

In the corn smut fungus Ustilago maydis the dimorphic switch from yeast like non-pathogenic to filamentous pathogenic phase is required for the mated fungal sporidia in order to complete the sexual life cycle. The haploid form of the fungus is self sterile and two sets of compatible genetic backgrounds with gene alterations were studied: 1) $a 1 b 1, a 2 b 2$ and 2) $a 1 b 2, a 2 b 1$. The mating locus $a$ that encodes mating pheromone and pheromone receptor is required for cell fusion and filamentation; mating locus $b$ that forms a functional heterodimeric transcription factor (bE1-bW2/bE2-bW1) is required for filamentation associated with mating, virulence and plant pathogenicity (Klosterman et al., 2007). Earlier it was observed that when genes encoding PAK-like kinases Smu1, Cla4 and a vital small GTPase Rho1, were altered in their expression, i.e., either disrupted or over-expressed then the associated phenotypes appeared to be genetic background specific (Pham et al., 2009), (Smith et al., 2004), (Leveleki et al., 2004), (Lovely et al., 2011). This study was intended to investigate if we could link the observed phenotypes to a particular mating locus either (a or type of $b$ allele) when such genes were altered. In the case of $\Delta$ cla 4 mutants as observed 
on PDA medium with activated charcoal it was reported that the reduction in mating was more pronounced when cla4 was deleted in a1b1 genetic background and mated with a2b2WT as compared to $a 1 b 1 \mathrm{WT}$ and $a 2 b 2 \mathrm{WT}$ mated strains. Also the $\Delta c / a 4$ mutant in a $1 b 1$ background had a tendency to clump together in liquid media and grew as branched and sepated hyphae. The a2b2 $\Delta$ cla 4 mutant divided by centrally placed septum (Leveleki et al., 2004). These phenotypes were examined in $a 1 b 2$ and $a 2 b 1$ genetic backgrounds for $\Delta c l a 4$ and we found that the effects reported earlier were due to genetic background but did not follow $a$ or $b$ locus designation when examined in the $a 1 b 2$ or a2b1 genetic background. Mating efficiency for $\Delta c / a 4$ mutants was the same as WT mated pair in $a 1 b 2$ and $a 2 b 1$ genetic backgrounds. In addition, morphological phenotypes for cells were also no longer associated with any particular mating locus (idiomorph or allele). Also, the filamentation defect was not observed in the a $1 b 2$ or a2b1 genetic backgrounds, $\Delta c / a 4$ mutant filaments were as long as their respective parental WT. Interestingly, the $\Delta$ cla 4 mutants in the $a 1 b 1$ and $a 2 b 2$ genetic backgrounds were significantly reduced in filamentation as compared to their respective parental WT. A similar genetic background specific behavior was observed for tho1 over-expression mutants. In $a 1 b 1$ and $a 2 b 2$ genetic background with rho 1 over-expression the reduction in mating was observed when a1b1WT was mated with $a 2 b 2$ having rho1 overexpressed, as seen on YPD medium with activated charcoal (Pham et al., 2009). When mating assay was conducted in the $a 1 b 2$ and $a 2 b 1$ genetic backgrounds for rho1 over-expression, the reduction in mating disappeared, i.e., all the 
mutants were equally as efficient as the WT mated pair. In stark contrast, for the $\Delta s m u 1$ mutants, the effects were not just because of genetic background, as evident from our results from activated charcoal plate mating assay, plant infection, and colony morphology. Earlier observations had revealed that when Smu1 was disrupted in the $a 1 b 1$ and $a 2 b 2$ genetic backgrounds then mating was reduced when a2b2 $\Delta s m u 1$ mated with $a 1 b 1 \mathrm{WT}$ was compared to a2b2WT mated with a1b1WT and $a 2 b 2 \mathrm{WT}$ mated with a1b1 $1 \mathrm{smu} 1$ (Figure 19).

Intensity of FUZZ on Activated Charcoal Plate

Genetic background $a 1 b 1, a 2 b 2$

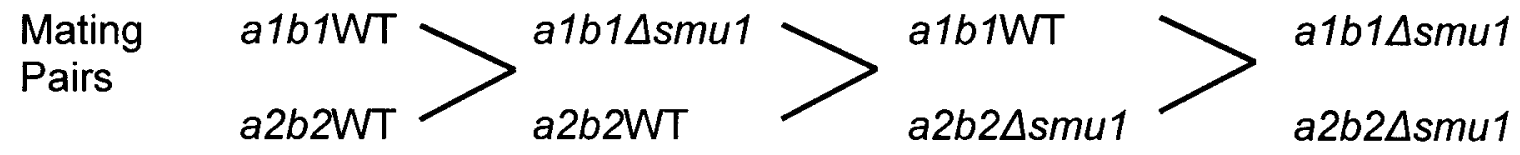

Intensity of FUZZ on Activated Charcoal Plate

Genetic background $a 2 b 1, a 1 b 2$

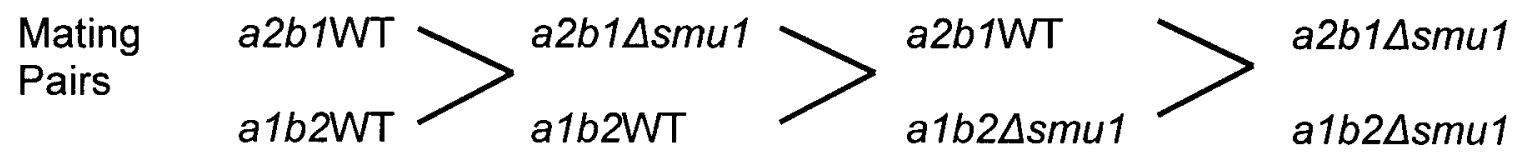

Figure 19: Comparison of intensity of fuzz on activated charcoal plate for $\Delta s m u 1$ mutants

When mating efficiency was examined for $\Delta s m u 1$ mutants in the $a 2 b 1$ and a1b2 genetic backgrounds then the reduction in mating was significantly greater in a1b2 with smu1 disruption mated with a2b1WT as compared with a1b2WT mated with a1b2WT and when both the mating partners had smu1 disruption. In 
addition, statistical analysis of disease indices data from plant infection also revealed that the disease index was reduced significantly when the disruption was present in a genetic background with the $b 2$ allele. We also analyzed data from plate mating assays and disease indices to know about the overall fold change in mating efficiency and disease index between both the compatible genetic background sets. Such an analysis indicated that although mating efficiency across the genetic background was same there was a difference in disease index between the genetic backgrounds used in these experiments. The genetic background by itself had an effect but presence of smu1 disruption further made a difference in disease indices. The a1b1WT mated with a2b2WT had an increased disease index compared with a1b2WT mated with a2b1WT. a2b2WT mated with a1b1 $\Delta s m u 1$ had a greater disease index than a1b2WT mated with a2b1 $1 s m u 1$. But in the case when smu1 disruption was present in a genetic background having the $b 2$ allele, then in both cases the disease index was the same and was lower than with infections where both partners were WT or where one partner had the deletion in a background with the $b 1$ allele. When we looked at mating efficiency for smu1 over-expression strains through activated charcoal plate mating assay, it did not go with any particular mating locus. But filamentation behavior was once again associated with smu1 disruption; it was observed that filamentation on SLAD was increased as compared to the respective WT when smu1 was disrupted in a background having $b 2$ allele i.e. $a 2 b 2 \Delta s m u 1$ was more filamentous as compared to a2b2WT and $a 1 b 2 \Delta s m u 1$ was more filamentous as compared to $a 1 b 2 \mathrm{WT}$. When strains 
over-expressing smu1 were examined then filamentation was increased when smu1 was over-expressed in a genetic background carrying $b 1$ allele.

In conclusion, it appeared that cla4 and rho1 mutants behaved independently of type of mating locus present and the effects were specific to other aspects of genetic background. In contrast, for smu1 there was some connection between smu1 and $b$ locus and the outcomes were dependent upon the environmental conditions. For mating and low ammonium conditions, $b 2$ allele displayed a co-ordinated effect when smu1 was disrupted. We hypothesize that $b$ alleles, may function as homodimers, e.g., bE1-bE1 and bW1-bW1, bE2$b E 2$ and bW2-bW2, or bE1-bE2 and bW1-bW2 and that their roles as transcription factors in such cases are affected by Smu1, activity. 


\section{CHAPTER III}

\section{GENERAL CONCLUSION}

The phytopathogenic fungus Ustilago maydis undergoes a dimorphic switch from a yeast like budding form to a filamentous form under conditions such as exposure to lipids, low $\mathrm{pH}$, nitrogen deficiency, and cues from its host plant maize during its sexual life cycle. The infection process in the host is an obligate aspect for completion of its sexual life cycle (Klosterman et al., 2007). The haploid form of the fungus is self-sterile, such cells require compatible mating partners for sexual reproduction. The fungus has a tetra-polar system and has two unlinked mating loci $a$ and $b$, with the former encoding pheromone precursor and receptor. Each $b$ allele encodes two homeodomain proteins, bE and bW. These two homeodomain proteins dimerize when they come from separate alleles to form a functional transcription factor, e.g., bE1-bW2 or bE2-bW1. The transcription factor up-regulates downstream targets that are involved in filamentation in response to mating, but also is involved in virulence and pathogenicity. The filament formed on the host maize plant is a dikaryon and is infectious. The dikarya multiply inside maize plant tissues and can cause tumors on any aerial part of the plant. Finally, the nuclei fuse and spores are produced. At the end, the tumor bursts open to release the diploid spores into the 
environment. Spores may then germinate under suitable conditions to undergo meiosis (Klosterman et al., 2007).

From a molecular stand point, a cell has to undergo many remarkable changes in order to keep up with the changing environment. The entire cytoskeleton has to be reorganized and there are many genes involved in such changes, including small GTPases, such as Rho1, which recruits protein complexes at the growing polar tip. Later these protein complexes are involved in depositing cell wall building material at the growing tip.

Another participant in the cellular response is that Smu1, a homologue of yeast PAK Ste20, that has an effect on mating in U. maydis. The smu1 disrupted strains in the $a 1 b 1$ and $a 2 b 2$ genetic backgrounds exhibited reduction in mating and reduction was more pronounced when the smu1 lesion was in the a2b2 mating partner. The smu1 mutants were also tested for disease index via corn plant infection and it was found that results were similar to those observed on charcoal plates, i.e., a $2 b 2 \Delta s m u 1$ mated with a1b1WT had a lower disease index as compared to WT mated partners and also as compared to when a2b2WT was mated with a1b1 1 smu1. Also, haploid smu1 disrupted mutants showed less filamentation on the low ammonium medium, SLAD. On the other hand, smu1 over-expression strains exhibited a slight increase in mating efficiency as compared to WT mating. The mating efficiency was increased when overexpression was in the a1b1 genetic background (Smith et al., 2004). 
All the above mentioned observations as well as others relating to the cla4 and rho1 genes led to the present investigation to find out if there was a link between the observed phenotypes and either the $a$ or $b$ mating loci. To address the question, additional genetic backgrounds (a1b2, a2b1) were selected and mating efficiency on activated charcoal plate with appropriate medium, disease index via corn plant infection, colony morphology, and cell morphology were studied. In the case of smu1 mutants, it was observed that mating efficiency was reduced when $a 1 b 2 \Delta s m u 1$ was mated with $a 2 b 1 \mathrm{WT}$ as compared to either WT mated partners or when compared to a2b1 $1 \Delta s m u 1$ mated with a1b2WT. Corn plants were also infected with mated smu1 disrupted strains to observe disease index. Once again the results from disease index were consistent with that we observed on activated charcoal plates, i.e., disease index was less when smu1 disruption was present in a partner with genetic background carrying the $b 2$ allele was mated with compatible WT. When mating efficiency was tested for the smu1 over-expression strain it appeared to be independent of genetic background. For smu1 mutants I also examined their behavior on low ammonium medium. I observed that smu1 disrupted mutants were more filamentous as compared to their respective parental WT when disruption was present in a genetic background carrying the $b 2$ allele.

In contrast to the case with smu1, for cla4 or rho1 mutants, it appeared that the effects observed primarily were just due to the genetic background and were independent of the mating type loci. 
The overall conclusion for smu1 mutants is that, with regard mating efficiency and disease index via plant infection, the phenotypic effects were more pronounced when smu1 disruption was present in a genetic background that had the $b 2$ allele. On the other hand, for filamentation behavior under low ammonium conditions, there was increase when the genetic background had the $b 2$ allele at the $b$ mating locus. These observations give arise to following hypotheses.

My first hypothesis is that in haploid $U$. maydis cells the bE or bW proteins also play an important role, possibly by transcribing genes involved in filamentation that are triggered in response to the environmental cues like low ammonium conditions. bE or bW monomers may also be involved in upregulation of filamentation via mating locus $a$ as there are $b$-binding sites (bbs) present on both the a mating loci (Klosterman et al., 2007). My second hypothesis is that Smu1 plays a role in filamentation behavior through $b$ locus in response to low ammonium conditions. This stems from results from the present study showed that Smu1 had a greater affect when disrupted in a background carrying $b 2$ allele. In the next section, I outline how these hypotheses may be tested.

\section{Future Directions}

The first hypothesis allows us to predict that both mating loci $a$ and $b$ are essential for filamentation under low ammonium conditions and if any of the two loci is deleted/disrupted then cells should not filament on SLAD. To test this hypothesis the following experiments could be undertaken: 
1) Obtain single colony streaks of the CL13 (a1 bW2 bE1) strain (Boelker et al., 1995) on SLAD; this strain should not filament because no homodimeric bE1-bE1 and bW1-bW1, bE2-bE2 and bW2-bW2, or bE1bE2 and bW1-bW2 would be available.

2) Obtain single colony streaks of $b$-null (Gillissen et al., 1992) mutant on SLAD and it should not filament. We already have preliminary results that support this prediction, in that when the $b$ locus is deleted in the FB1 background, such strains fail to filament on SLAD (J Paul et al, in preparation).

3) Obtain single colony streaks of a strain with either bE or bW deletion (i.e., the strain will have either bE or just bW alone) (Gillissen et al., 1992) on SLAD and this strain should filament.

4) Generate a strain that is an a-null mutant and the mutant should not filament on SLAD.

To test the hypothesis that Smu1 interacts with the $b$ locus, I propose the following experiments:

a) Generate a double knockout for bE2 and smu1 in genetic background that has $b 2$ allele at $b$ locus and test on SLAD for filamentation behavior and compare with single knockouts for bE2 and smu1.

b) Generate a double knockout for bW2 and smu1 in genetic background that has $b 2$ allele at $b$ locus and test on SLAD for filamentation behavior and compare with single knockouts for bW2 and smu1. 


\section{REFERENCES}

Adachi K., Nanba H., Otsuka M., Kuroda H. (1988) Blood pressure-lowering activity present in the fruit body of Grifola frondosa (maitake). I. Chemical \& pharmaceutical bulletin 36:1000-6.

Agarwal C., Schultz D.J., Perlin M.H. (2010) Two phosphodiesterases from ustilago maydis share structural and biochemical properties with nonfungal phosphodiesterases. Frontiers in microbiology 1:127. DOI: 10.3389/fmicb.2010.00127.

Ballon D.R., Flanary P.L., Gladue D.P., Konopka J.B., Dohlman H.G., Thorner J. (2006) DEP-domain-mediated regulation of GPCR signaling responses. Cell 126:1079-93. DOI: 10.1016/j.cell.2006.07.030.

Banuett F. (1995) GENETICS OF USTILAGO MAYDIS, A FUNGAL PATHOGEN THAT INDUCES TUMORS IN MAIZE. Annual Review of Genetics 29:179208.

Banuett F., Herskowitz I. (1989) Different a alleles of Ustilago maydis are necessary for maintenance of filamentous growth but not for meiosis. Proceedings of the National Academy of Sciences of the United States of America 86:5878-82.

Bardwell L. (2006) Mechanisms of MAPK signalling specificity. Biochemical Society transactions 34:837-41. DOI: 10.1042/BST0340837.

Benedict R.G., Brady L.R. (1972) Antimicrobial activity of mushroom metabolites. Journal of pharmaceutical sciences 61:1820-2.

Benton B.K., Tinkelenberg A., Gonzalez I., Cross F.R. (1997) Cla4p, a Saccharomyces cerevisiae Cdc42p-activated kinase involved in cytokinesis, is activated at mitosis. Molecular and cellular biology 17:506776.

Boelker M., Genin S., Lehmler C., Kahmann R. (1995) Genetic regulation of mating and dimorphism in Ustilago maydis. CANADIAN JOURNAL OF BOTANY 73:S320. 
Boenisch M.J., Schafer W. (2011) Fusarium graminearum forms mycotoxin producing infection structures on wheat. BMC plant biology 11:110. DOI: 10.1186/1471-2229-11-110.

Bolker M. (2001) Ustilago maydis--a valuable model system for the study of fungal dimorphism and virulence. Microbiology 147:1395-401.Brachmann A., Konig J., Julius C., Feldbrugge M. (2004) A reverse genetic approach for generating gene replacement mutants in Ustilago maydis. Molecular genetics and genomics: MGG 272:216-26. DOI: 10.1007/s00438-0041047-z.

Brauer L., Brandt W., Schulze D., Zakharova S., Wessjohann L. (2008) A structural model of the membrane-bound aromatic prenyltransferase UbiA from E. coli. Chembiochem : a European journal of chemical biology 9:982-92. DOI: 10.1002/cbic.200700575.

Carbo N., Perez-Martin J. (2008) Spa2 is required for morphogenesis but it is dispensable for pathogenicity in the phytopathogenic fungus Ustilago maydis. Fungal genetics and biology : FG \& B 45:1315-27. DOI: 10.1016/j.fgb.2008.06.010.

Chang C.H., Yu F.Y., Wu T.S., Wang L.T., Liu B.H. (2011) Mycotoxin citrinin induced cell cycle G2/M arrest and numerical chromosomal aberration associated with disruption of microtubule formation in human cells. Toxicological sciences : an official journal of the Society of Toxicology 119:84-92. DOI: 10.1093/toxsci/kfq309.

Conant N.F. (1941) Cultural Study of the Life-Cycle of Histoplasma capsulatum Darling 1906. Journal of bacteriology 41:563-79.

Dadachova E., Bryan R.A., Huang X., Moadel T., Schweitzer A.D., Aisen P., Nosanchuk J.D., Casadevall A. (2007) lonizing radiation changes the electronic properties of melanin and enhances the growth of melanized fungi. PloS one 2:e457. DOI: 10.1371/journal.pone.0000457.

Fedler M., Luh K.-S., Stelter K., Nieto-Jacobo F., Basse C.W. (2009) The a2 Mating-Type Locus Genes Iga2 and rga2 Direct Uniparental Mitochondrial DNA (mtDNA) Inheritance and Constrain mtDNA Recombination During Sexual Development of Ustilago maydis. Genetics 181:847-860. DOl: 10.1534/genetics.108.096859.

Fries B.C., Taborda C.P., Serfass E., Casadevall A. (2001) Phenotypic switching of Cryptococcus neoformans occurs in vivo and influences the outcome of infection. The Journal of clinical investigation 108:1639-1648.

Froufe H.J., Abreu R.M., Ferreira I.C. (2011) Using molecular docking to investigate the anti-breast cancer activity of low molecular weight 
compounds present on wild mushrooms. SAR and QSAR in environmental research 22:315-28. DOI: 10.1080/1062936X.2011.569897.

Fujita A., Tonouchi A., Hiroko T., Inose F., Nagashima T., Satoh R., Tanaka S. (1999) Hsl7p, a negative regulator of Ste20p protein kinase in the Saccharomyces cerevisiae filamentous growth-signaling pathway. Proceedings of the National Academy of Sciences of the United States of America 96:8522-7.

Garcia-Muse T., Steinberg G., Perez-Martin J. (2004) Characterization of B-type cyclins in the smut fungus Ustilago maydis: roles in morphogenesis and pathogenicity. Journal of cell science 117:487-506. DOI: 10.1242/jcs.00877.

Garcia-Pedrajas M.D., Nadal M., Bolker M., Gold S.E., Perlin M.H. (2008) Sending mixed signals: redundancy vs. uniqueness of signaling components in the plant pathogen, Ustilago maydis. Fungal genetics and biology: FG \& B 45 Suppl 1:S22-30. DOl: 10.1016/j.fgb.2008.04.007.

Gillissen B., Bergemann J., Sandmann C., Schroeer B., Bolker M., Kahmann R. (1992) A two-component regulatory system for self/non-self recognition in Ustilago maydis. Cell 68:647-57.

Gold S.E., Brogdon S.M., Mayorga M.E., Kronstad J.W. (1997) The Ustilago maydis regulatory subunit of a CAMP-dependent protein kinase is required for gall formation in maize. The Plant cell 9:1585-94. DOl: 10.1105/tpc.9.9.1585.

Gombert S., Asta J., Seaward M.R. (2005) The use of autecological and environmental parameters for establishing the status of lichen vegetation in a baseline study for a long-term monitoring survey. Environmental pollution 135:501-14. DOI: 10.1016/j.envpol.2004.10.010.

Hicke L., Zanolari B., Riezman H. (1998) Cytoplasmic tail phosphorylation of the alpha-factor receptor is required for its ubiquitination and internalization. The Journal of cell biology 141:349-58.

Hofmann C., Shepelev M., Chernoff J. (2004) The genetics of Pak. Journal of cell science 117:4343-54. DOI: 10.1242/jcs.01392.

Holliday R. (2004) Early studies on recombination and DNA repair in Ustilago maydis. DNA repair 3:671-82. DOI: 10.1016/j.dnarep.2004.02.002.

Holly S.P., Blumer K.J. (1999) PAK-family kinases regulate cell and actin polarization throughout the cell cycle of Saccharomyces cerevisiae. The Journal of cell biology 147:845-56. 
Hoog G.S.d. (2000) Atlas of clinical fungi. 2nd ed. Centraalbureau voor Schimmelcultures, Utrecht.

Ismail Y., McCormick S., Hijri M. (2011) A fungal symbiont of plant-roots modulates mycotoxin gene expression in the pathogen Fusarium sambucinum. PloS one 6:e17990. DOI: 10.1371/journal.pone.0017990.

Kahmann R., Kämper J. (2004) Ustilago maydis: how its biology relates to pathogenic development. New Phytologist 164:31-42. DOI: 10.1111/j.1469-8137.2004.01156.x.

Keniry M.E., Sprague G.F., Jr. (2003) Identification of p21-activated kinase specificity determinants in budding yeast: a single amino acid substitution imparts Ste20 specificity to Cla4. Molecular and cellular biology 23:156980.

Klose J., de Sa M.M., Kronstad J.W. (2004) Lipid-induced filamentous growth in Ustilago maydis. Molecular microbiology 52:823-35. DOI: 10.1111/j.13652958.2004.04019.x.

Klosterman S.J., Perlin M.H., Garcia-Pedrajas M., Covert S.F., Gold S.E. (2007) Genetics of Morphogenesis and Pathogenic Development of Ustilago maydis, in: C. D. Jay (Ed.), Advances in Genetics, Academic Press. pp. 147.

Lamson R.E., Winters M.J., Pryciak P.M. (2002) Cdc42 regulation of kinase activity and signaling by the yeast p21-activated kinase Ste20. Molecular and cellular biology 22:2939-51.

Lefkowitz R.J. (2004) Historical review: a brief history and personal retrospective of seven-transmembrane receptors. Trends in pharmacological sciences 25:413-22. DOI: 10.1016/j.tips.2004.06.006.

Lengeler K.B., Davidson R.C., D'Souza C., Harashima T., Shen W.C., Wang P., Pan X., Waugh M., Heitman J. (2000) Signal transduction cascades regulating fungal development and virulence. Microbiology and molecular biology reviews : MMBR 64:746-85.

Leveleki L., Mahlert M., Sandrock B., Bolker M. (2004) The PAK family kinase Cla4 is required for budding and morphogenesis in Ustilago maydis. Molecular microbiology 54:396-406. DOI: 10.1111/j.13652958.2004.04296.x.

Lovely C.B., Aulakh K.B., Perlin M.H. (2011) Role of Hsl7 in morphology and pathogenicity and its interaction with other signaling components in the plant pathogen Ustilago maydis. Eukaryotic cell 10:869-83. DOI: 10.1128/EC.00237-10. 
Mahmoud A.L. (1993) Dermatophytes and other associated fungi isolated from ringworm lesions of camels. Folia microbiologica 38:505-8.

Mayorga M.E., Gold S.E. (1999) A MAP kinase encoded by the ubc3 gene of Ustilago maydis is required for filamentous growth and full virulence. Molecular microbiology 34:485-97.

Mazur P., Baginsky W. (1996) In vitro activity of 1,3-beta-D-glucan synthase requires the GTP-binding protein Rho1. The Journal of biological chemistry $271: 14604-9$.

Mueller O., Kahmann R., Aguilar G., Trejo-Aguilar B., Wu A., de Vries R.P. (2008) The secretome of the maize pathogen Ustilago maydis. Fungal Genetics and Biology 45, Supplement 1:S63-S70. DOI: 10.1016/j.fgb.2008.03.012.

Nadal M., Garcia-Pedrajas M.D., Gold S.E. (2008) Dimorphism in fungal plant pathogens. FEMS microbiology letters 284:127-34. DOI: 10.1111/j.15746968.2008.01173.x.

Ozaki K., Tanaka K., Imamura H., Hihara T., Kameyama T., Nonaka H., Hirano H., Matsuura Y., Takai Y. (1996) Rom1p and Rom2p are GDP/GTP exchange proteins (GEPs) for the Rho1p small GTP binding protein in Saccharomyces cerevisiae. The EMBO journal 15:2196-207.

Pham C.D., Yu Z., Sandrock B., Bolker M., Gold S.E., Perlin M.H. (2009) Ustilago maydis Rho1 and 14-3-3 homologues participate in pathways controlling cell separation and cell polarity. Eukaryotic cell 8:977-89. DOI: 10.1128/EC.00009-09.

Ristaino J.B. (2002) Tracking historic migrations of the Irish potato famine pathogen, Phytophthora infestans. Microbes and infection / Institut Pasteur 4:1369-77.

Ruiz-Herrera J., Martinez-Espinoza A.D. (1998) The fungus Ustilago maydis, from the aztec cuisine to the research laboratory. International microbiology : the official journal of the Spanish Society for Microbiology $1: 149-58$

Schirawski J., Heinze B., Wagenknecht M., Kahmann R. (2005) Mating type loci of Sporisorium reilianum: novel pattern with three $a$ and multiple $b$ specificities. Eukaryotic cell 4:1317-27. DOI: 10.1128/EC.4.8.13171327.2005 .

Smith D.G., Garcia-Pedrajas M.D., Hong W., Yu Z., Gold S.E., Perlin M.H. (2004) An ste20 homologue in Ustilago maydis plays a role in mating and pathogenicity. Eukaryotic cell 3:180-9. 
Smits G.J., van den Ende H., Klis F.M. (2001) Differential regulation of cell wall biogenesis during growth and development in yeast. Microbiology 147:781-94.

Strathern J.N., Klar A.J.S., Hicks J.B., Abraham J.A., Ivy J.M., Nasmyth K.A., McGill C. (1982) Homothallic switching of yeast mating type cassettes is initiated by a double-stranded cut in the MAT locus. Cell 31:183-192.

Takahashi S., Pryciak P.M. (2007) Identification of Novel Membrane-binding Domains in Multiple Yeast Cdc42 Effectors. Molecular Biology of the Cell 18:4945-4956. DOI: 10.1091/mbc.E07-07-0676.

Takai Y., Sasaki T., Matozaki T. (2001) Small GTP-Binding Proteins. Physiological Reviews 81:153-208.

Weinzierl G., Leveleki L., Hassel A., Kost G., Wanner G., Bolker M. (2002) Regulation of cell separation in the dimorphic fungus Ustilago maydis. Molecular microbiology 45:219-31.

Yu J.Y., Zheng Z.H., Son Y.O., Shi X., Jang Y.O., Lee J.C. (2011) Mycotoxin zearalenone induces AIF- and ROS-mediated cell death through p53- and MAPK-dependent signaling pathways in RAW264.7 macrophages.

Toxicology in vitro : an international journal published in association with BIBRA 25:1654-63. DOI: 10.1016/j.tiv.2011.07.002. 


\section{APPENDIX}

Table A: $p$-values from Statistical Analysis for Activated Charcoal Plate Mating assays

\begin{tabular}{|c|c|c|}
\hline \multicolumn{3}{|l|}{ Activated Charcoal Plate Mating Assay } \\
\hline Mating Pair & Estimate & p-value \\
\hline$a 1 b 1 \mathrm{WT}-a 2 b 2 \mathrm{WT}$ vs $a 2 b 2 \mathrm{WT}-\mathrm{a} 1 b 1 \Delta s m u 1$ & 8.9475 & 0.1795 \\
\hline$a 1 b 1 W T-a 2 b 2 W T$ vs a1b1WT-a2b2 $1 s m u 1$ & 34.6051 & 0.0018 \\
\hline$a 1 b 1 W T-a 2 b 2 W T$ vs a2b2 & 58.5053 & 0.0002 \\
\hline$a 2 b 2 \mathrm{WT}-a 1 b 1 \Delta s m u 1$ vs $a 1 b 1 \mathrm{WT}-a 2 b 2 \Delta s m u 1$ & 25.6576 & 0.0066 \\
\hline$a 2 b 2 W T-a 1 b 1 \Delta s m u 1$ vs a2b2 $\Delta s m u 1-a 1 b 1 \Delta s m u 1$ & 49.5578 & 0.0003 \\
\hline$a 1 b 1 \mathrm{WT}-a 2 b 2 \Delta s m u 1$ vs $a 2 b 2 \Delta s m u 1-a 1 b 1 \Delta s m u 1$ & 23.9002 & 0.0088 \\
\hline$a 1 b 2 W T-a 2 b 1 W T$ vs a1b2WT-a2b1 1 smu1 & 21.6889 & $<0.0001$ \\
\hline$a 1 b 2 W T-a 2 b 1 W T$ vs a2b1WT-a1b2 $1 s m u 1$ & 59.3965 & $<0.0001$ \\
\hline$a 1 b 2 W T-a 2 b 1 W T$ vs a1b2 $1 s m u 1-a 2 b 1 \Delta s m u 1$ & 70.5796 & $<0.0001$ \\
\hline$a 1 b 2 W T-a 2 b 1 \Delta s m u 1$ vs a2b1WT-a1b2 $\Delta s m u 1$ & 37.7076 & $<0.0001$ \\
\hline$a 1 b 2 W T-a 2 b 1 \Delta s m u 1$ vs a $1 b 2 \Delta s m u 1-a 2 b 1 \Delta s m u 1$ & 48.8908 & $<0.0001$ \\
\hline$a 2 b 1 W T-a 1 b 2 \Delta s m u 1$ vs a $1 b 2 \Delta s m u 1-a 2 b 1 \Delta s m u 1$ & 11.1831 & 0.0044 \\
\hline$a 1 b 1 \mathrm{WT}-a 2 b 2 \mathrm{WT}$ vs $a 2 b 2 \mathrm{WT}-a 1 b 1$ smu1otef & -15.2600 & 0.0736 \\
\hline a1b1WT-a2b2WT vs a1b1WT-a2b2smu1otef & -1.9050 & 0.7894 \\
\hline a1b1WT-a2b2WT vs a2b2smu1otef-a1b1smu1otef & -29.9800 & 0.0068 \\
\hline$a 2 b 2 \mathrm{WT}-a 1 b 1$ smu1otef vs a1b1WT-a2b2smu1otef & 13.3550 & 0.1052 \\
\hline$a 2 b 2 \mathrm{WT}-a 1 b 1 \mathrm{smu10tef}$ vs a2b2otefsmu1-a1b1smu1otef & -14.7200 & 0.0814 \\
\hline
\end{tabular}




\begin{tabular}{|c|c|c|}
\hline$a 1 b 1$ WT-a2b2smu1otef vs a2b2smu1otef-a1b1smu1otef & -28.0750 & 0.0089 \\
\hline$a 1 b 2 \mathrm{WT}-a 2 b 1 \mathrm{WT}$ vs a1b2WT-a2b1smu1otef & -1.2845 & 0.8513 \\
\hline$a 1 b 2 W T-a 2 b 1 W T$ vs a2b1WT-a1b2smu1otef & 9.6555 & 0.1980 \\
\hline$a 1 b 2 W T-a 2 b 1 W T$ vs a1b2smu1otef-a2b1smu1otef & 6.3955 & 0.3708 \\
\hline$a 1 b 2 \mathrm{WT}-a 2 b 1$ smu1otef vs a2b1WT-a1b2smu1otef & 10.9400 & 0.1535 \\
\hline$a 1 b 2 W T-a 2 b 1 s m u 1 o t e f$ vs a1b2smu1otef-a2b1smu1otef & 7.6800 & 0.2910 \\
\hline$a 2 b 1 \mathrm{WT}-\mathrm{a} 1 \mathrm{~b} 2 \mathrm{smu1otef}$ vs a1b2smu1otef-a2b1smu1otef & -3.2600 & 0.6377 \\
\hline$a 1 b 1 \mathrm{WT}-a 2 b 2 \mathrm{WT}$ vs $a 2 b 2 \mathrm{WT}-\mathrm{a} 1 b 1 \Delta c / a 4$ & 33.7000 & $<0.0001$ \\
\hline$a 1 b 1 \mathrm{WT}-a 2 b 2 \mathrm{WT}$ vs a1b1WT-a2b2 $\Delta c / a 4$ & 25.0750 & 0.0013 \\
\hline$a 1 b 1 W T-a 2 b 2 W T$ vs $a 2 b 2 \Delta c l a 4-a 1 b 1 \Delta c l a 4$ & 35.2750 & $<0.0001$ \\
\hline$a 2 b 2 W T-a 1 b 1 \Delta c l a 4$ vs a1b1WT-a2b2 $\Delta c l a 4$ & -8.6250 & 0.2099 \\
\hline$a 2 b 2 W T-a 1 b 1 \Delta c l a 4$ vs $a 2 b 2 \Delta c l a 4-a 1 b 1 \Delta c l a 4$ & 1.5750 & 0.8152 \\
\hline$a 1 b 1 W T-a 2 b 2 \Delta c l a 4$ vs a2b2 $\Delta$ cla4-a1b1 $\Delta c l a 4$ & 10.2000 & 0.1413 \\
\hline$a 1 b 2 W T-a 2 b 1 \mathrm{WT}$ vs a1b2WT-a2b1 $\Delta c / a 4$ & -0.9500 & 0.8739 \\
\hline$a 1 b 2 W T-a 2 b 1 W T$ vs a2b1WT-a1b2 & 9.0750 & 0.1409 \\
\hline$a 1 b 2 W T-a 2 b 1 W T$ vs a1b2 $\Delta c l a 4-a 2 b 1 \Delta c l a 4$ & 11.5750 & 0.0648 \\
\hline$a 1 b 2 W T-a 2 b 1 \Delta c l a 4$ vs a2b1WT-a1b2 $1 c l a 4$ & 10.0250 & 0.1059 \\
\hline$a 1 b 2 W T-a 2 b 1 \Delta c / a 4$ vs a $1 b 2 \Delta c l a 4-a 2 b 1 \Delta c l a 4$ & 12.5250 & 0.0473 \\
\hline$a 2 b 1 W T-a 1 b 2 \Delta c l a 4$ vs a $1 b 2 \Delta c l a 4-a 2 b 1 \Delta c l a 4$ & 2.5000 & 0.6768 \\
\hline$a 1 b 1 \mathrm{WT}-a 2 b 2 \mathrm{WT}$ vs a2b2WT-a1b1Urho1 & 19.2000 & 0.1222 \\
\hline a1b1WT-a2b2WT vs a1b1WT-a2b2Urho1 & 40.3500 & 0.0038 \\
\hline a1b1WT-a2b2WT vs a2b2Urho1-a1b1Urho1 & 39.5000 & 0.0044 \\
\hline a2b2WT-a1b1Urho1 vs a1b1WT-a2b2Urho1 & 21.1500 & 0.0914 \\
\hline a2b2WT-a1b1Urho1 vs a2b2Urho1-a1b1Urho1 & 20.3000 & 0.1039 \\
\hline a1b1WT-a2b2Urho1 vs a2b2Urho1-a1b1Urho1 & -0.8500 & 0.9430 \\
\hline$a 1 b 2 \mathrm{WT}-a 2 b 1 \mathrm{WT}$ vs a1b2WT-a2b1urho1 & -0.6000 & 0.9544 \\
\hline
\end{tabular}




\begin{tabular}{|c|c|c|}
\hline$a 1 b 2 \mathrm{WT}-a 2 b 1 \mathrm{WT}$ vs a2b1WT-a1b2Urho1 & -2.6500 & 0.8008 \\
\hline$a 1 b 2 W T-a 2 b 1 W T$ vs a1b2Urho1-a2b1Urho1 & -11.6100 & 0.2718 \\
\hline \multicolumn{3}{|l|}{$a 1 b 2 W T-a 2 b 1 U r h o 1$ vs a2b1WT-a1b2Urho1 } \\
\hline$a 1 b 2 \mathrm{WT}-a 2 b 1$ Urho1 vs a1b2urho1-a2b1Urho1 & -11.0100 & 0.2970 \\
\hline a2b1WT-a1b2Urho1 vs a1b2Urho1-a2b1Urho1 & -8.9600 & 0.3952 \\
\hline \multicolumn{3}{|c|}{ Disease indices from Plant Infection for $\Delta s m u 1$ mutants } \\
\hline$a 1 b 1 \mathrm{WT}-a 2 b 2 \mathrm{WT}$ vs a2b2WT-a1b1 $\mathrm{s} m u 1$ & 0.8011 & 0.0172 \\
\hline a1b1WT-a2b2WT vs a1b1WT-a2b2 1 smu1 & 1.1011 & 0.0013 \\
\hline$a 1 b 1 \mathrm{WT}-a 2 b 2 \mathrm{WT}$ vs $a 2 b 2 \Delta s m u 1-a 1 b 1 \Delta s m u 1$ & 1.1344 & 0.0009 \\
\hline$a 2 b 2 \mathrm{WT}-a 1 b 1 \Delta s m u 1$ vs $a 1 b 1 \mathrm{WT}-\mathrm{a} 2 \mathrm{~b} 2 \Delta s m u 1$ & 0.3000 & 0.3475 \\
\hline$a 2 b 2 W T-a 1 b 1 \Delta s m u 1$ vs a2b2 & 0.3333 & 0.2969 \\
\hline$a 1 b 1 \mathrm{WT}-a 2 b 2 \Delta s m u 1$ vs $a 2 b 2 \Delta s m u 1-a 1 b 1 \Delta s m u 1$ & 0.0333 & 0.9167 \\
\hline$a 1 b 2 W T-a 2 b 1 W T$ vs a1b2WT-a2b1 1 smu1 & 0.1333 & 0.1723 \\
\hline a1b2WT-a2b1WT vs a2b1WT-a1b2 $\Delta$ smu1 & 0.2333 & 0.0181 \\
\hline$a 1 b 2 W T-a 2 b 1 W T$ vs a1b2 & 0.3000 & 0.0026 \\
\hline$a 1 b 2 W T-a 2 b 1 \Delta s m u 1$ vs a2b1WT-a1b2 $1 s m u 1$ & 0.1000 & 0.3049 \\
\hline$a 1 b 2 \mathrm{WT}-a 2 b 1 \Delta s m u 1$ vs a1b2 $2 s m u 1-a 2 b 1 \Delta s m u 1$ & 0.1667 & 0.0889 \\
\hline$a 2 b 1 W T-a 1 b 2 \Delta s m u 1$ vs a $1 b 2 \Delta s m u 1-a 2 b 1 \Delta s m u 1$ & 0.0666 & 0.4932 \\
\hline
\end{tabular}




\section{CURRICULM VITAE}

\section{KAVITA BURMAN AULAKH}

154, Kentuck Road, Apt C 21,

Danville, Virginia- 24540

434-548-3709

kavita.aulakh@gmail.com
139, Life Sciences Building

Department of Biology

Belknap Campus

University of Louisville

Louisville, Kentucky-40292

\section{Education}

\begin{tabular}{|c|c|c|}
\hline $\begin{array}{l}\text { Degreel } \\
\text { Diploma }\end{array}$ & $\begin{array}{l}\text { University / Year of } \\
\text { Graduation }\end{array}$ & Course work \\
\hline $\begin{array}{l}\text { MS } \\
\text { (Molecular, } \\
\text { Cellular, and } \\
\text { Developmental } \\
\text { Biology) }\end{array}$ & $\begin{array}{l}\text { Dept. Of Biology, } \\
\text { University of Louisville, } \\
\text { Kentucky, United States } \\
\text { /May } 2012\end{array}$ & $\begin{array}{l}\text { Advanced Gene } \\
\text { Structure/Function, Cell Biology, } \\
\text { Advanced biostatistics, Advanced } \\
\text { Intermediate metabolism, } \\
\text { Advanced Evolution, Advanced } \\
\text { Environmental Physiology } \\
\text { Thesis Titled "Specific b alleles } \\
\text { matter in phytopathogenic } \\
\text { Ustilago maydis" }\end{array}$ \\
\hline $\begin{array}{l}\text { B.Sc. Botany } \\
\text { (Hons.) }\end{array}$ & $\begin{array}{l}\text { University of Delhi, India } \\
\text { /2003 }\end{array}$ & $\begin{array}{l}\text { Botany (major), Zoology, } \\
\text { Chemistry (Inorganic, Organic, } \\
\text { Physical chemistry), English, } \\
\text { History Of Science }\end{array}$ \\
\hline $\begin{array}{l}\text { Bachelor's In } \\
\text { Education }\end{array}$ & $\begin{array}{l}\text { Sri Guru Gobind Singh } \\
\text { Indraprastha University, } \\
\text { India /2006 }\end{array}$ & $\begin{array}{l}\text { Philosophy, Psychology, } \\
\text { Curriculum, System. \& Issues., } \\
\text { Computer, Life sciences, } \\
\text { Integrated sciences, Education for } \\
\text { children with Special Needs }\end{array}$ \\
\hline $\begin{array}{l}\text { Advanced } \\
\text { Diploma In } \\
\text { Multimedia }\end{array}$ & $\begin{array}{l}\text { Aptech University, India } \\
\text { /2007 }\end{array}$ & $\begin{array}{l}\text { Graphics, Authoring Multimedia, } \\
\text { Animation, Multimedia for Web \& } \\
\text { Games, and Maya }\end{array}$ \\
\hline
\end{tabular}


Work Experience

\begin{tabular}{lll}
\hline Institution & Designation & Duration \\
\hline Dept. of Biology, University of Louisville, & ${ }^{*}$ Graduate & Jan 2010-Apr \\
Kentucky -40292, United States & $\begin{array}{l}\text { Teaching } \\
\text { Assistant }\end{array}$ & 2012 \\
& & \\
Sri Guru Nanak Public School, Delhi- & •TGT Science & Oct 2007-Dec \\
$\begin{array}{l}\text { 110033, India } \\
\text { Kasturi Ram International School, Delhi- }\end{array}$ & •TGT Science & $\begin{array}{l}\text { Apr 2007-Oct } \\
\text { 110040, India }\end{array}$ \\
$\begin{array}{l}\text { North Delhi Public School, Delhi-110052, } \\
\text { India }\end{array}$ & •TGT Science & Aug 2006-Mar \\
& & 2007 \\
\hline
\end{tabular}

*GTA for Genetics and Molecular Biology Laboratory (Lab for Bio-Majors)

-TGT: Trained Graduate Teacher

\section{Lab Skills:}

Currently, I am involved with bioengineering, fungal strains. I am trained in molecular biology techniques like: DNA isolation, Primer design, PCR, DNA sequencing, Restriction digestion, Gene cloning, Agarose gel electrophoresis, SDS-PAGE, Protein isolation, spectrophotometer, Southern blots, Preparing bacterial competent cells and Protoplasts of fungal cells, Bacterial and Fungal transformation, Yeast-two hybrid assay, Microscopy, Preparation of lab reagents.

\section{Current Thesis Project:}

Under guidance of Dr. Michael $\mathrm{H}$. Perlin, I am working with a basidiomycete fungus, Ustilago maydis. In order to complete its sexual life cycle $U$. maydis infects maize plants, causing gall formation on all aerial parts. There are two mating loci -"locus $a$ " and "locus $b$ ". The strains under study have mating type's $a 1 b 1, a 2 b 2, a 1 b 2$ and $a 2 b 1.1$ am trying to find out which mating locus is responsible for the observed unusual phenotypes in mutants either having gene knockout or over expression of specific genes whose products are components of conserved signaling cascades like: MAPK, PKA pathway.

\section{Other projects:}

In the present lab at UofL,

1. Investigation of interaction between $\mathrm{Hs} / 7$ (arginine methyltransferase) and Cla4 (p21-activated kinase) proteins of $U$. maydis. To determine interaction, Yeast two-hybrid assay was conducted. Results published in Eukaryotic Cell, May 2011 
2. I studied biochemical activity of a putative phosphodiesterase gene of Ustilago maydis. The gene was expressed in yeast system. HPLC was used to determine activity.

During my BS, I got an opportunity to work on a project "Sex expression and reversal in Morus alba (mulberry) under in-vitro conditions", under supervision of Dr. S.B. Babbar, professor at the Department of Botany, University of Delhi, India. While performing experiments, I learned tissue culture techniques and other laboratory skills (2002-2003).

In addition, I voluntarily served in the collection of field data for Dr. Javed lqbal, Research Scientist at Institute for Advanced Learning and Research, Danville, Virginia, working on potential bio-fuel crop - Helianthus tuberosus (Jerusalem artichoke) (2008-2009).

\section{Abstracts \& Posters:}

Ben Lovely, Gregory E. Shaw, Kavita B Aulakh, and Michael H. Perlin. University of Louisville, Department of Biology, Program on Disease Evolution, Louisville, Kentucky, USA

Mating Type Specific Signaling in Ustilago maydis.

Presented at the $26^{\text {th }}$ Fungal Genetics Conference, Asilomar, CA. March 2011

\section{Publications:}

Lovely CB, Aulakh KB, \& Perlin MH (2011) Role of Hsl7 in morphology and pathogenicity and its interaction with other signaling components in the plant pathogen Ustilago maydis. Eukaryot Cell 10(7):869-883.

\section{References:}

\begin{tabular}{ll}
\hline Institution & \\
\hline $\begin{array}{l}\text { Dr. Michael H. Perlin } \\
\text { Professor } \\
\text { (Advisor) }\end{array}$ & $\begin{array}{l}\text { Department of Biology, Division: Molecular, Cellular } \\
\text { and Developmental Biology, University of Louisville, } \\
\text { Kentucky, USA }\end{array}$ \\
& $\begin{array}{l}\text { Email: mhperl01@exchange.louisville.edu Phone: } \\
502-852-5944 \\
\text { Physical address: 139, Life Sciences Building, } \\
\text { Department of Biology, Belknap campus, University of } \\
\text { Louisville, Kentucky- 40292 }\end{array}$ \\
& \\
Dr. David J. Schultz & $\begin{array}{l}\text { Department of Biology, Division: Molecular, Cellular } \\
\text { associate professor }\end{array}$ \\
\hline
\end{tabular}




\begin{tabular}{ll}
\hline (Committee Member) & Kentucky, USA \\
& $\begin{array}{l}\text { Email: djschu02@exchange.louisville.edu Phone: } \\
502-852-5938\end{array}$ \\
& $\begin{array}{l}\text { Physical address: 139, Life Sciences Building, } \\
\text { Department of Biology, Belknap campus, University of } \\
\text { Louisville, Kentucky- 40292 }\end{array}$ \\
& Department of Microbiology and Immunology, \\
Dr. Jill Suttles & University of Louisville, Kentucky, USA \\
Professor & Emmittee Member) \\
& $\begin{array}{l}\text { Emyil: jill.suttles@louisville.edu Phone: 502-852-5144 } \\
\text { Physical address: Room 316A, 319 Abraham Flexner } \\
\text { Wouisville, Kentucky - 40202 }\end{array}$ \\
\hline
\end{tabular}

